\title{
Cholinergic modulation of auditory processing, sensory gating and novelty detection in human participants
}

Citation for published version (APA):

Klinkenberg, I., Blokland, A., Riedel, W. J., \& Sambeth, A. (2013). Cholinergic modulation of auditory processing, sensory gating and novelty detection in human participants. Psychopharmacology, 225(4), 903-921. https://doi.org/10.1007/s00213-012-2872-0

Document status and date:

Published: 01/02/2013

DOI:

10.1007/s00213-012-2872-0

Document Version:

Publisher's PDF, also known as Version of record

Document license:

Taverne

Please check the document version of this publication:

- A submitted manuscript is the version of the article upon submission and before peer-review. There can be important differences between the submitted version and the official published version of record.

People interested in the research are advised to contact the author for the final version of the publication, or visit the DOI to the publisher's website.

- The final author version and the galley proof are versions of the publication after peer review.

- The final published version features the final layout of the paper including the volume, issue and page numbers.

Link to publication

\footnotetext{
General rights rights.

- You may freely distribute the URL identifying the publication in the public portal. please follow below link for the End User Agreement:

www.umlib.nl/taverne-license

Take down policy

If you believe that this document breaches copyright please contact us at:

repository@maastrichtuniversity.nl

providing details and we will investigate your claim.
}

Copyright and moral rights for the publications made accessible in the public portal are retained by the authors and/or other copyright owners and it is a condition of accessing publications that users recognise and abide by the legal requirements associated with these

- Users may download and print one copy of any publication from the public portal for the purpose of private study or research.

- You may not further distribute the material or use it for any profit-making activity or commercial gain

If the publication is distributed under the terms of Article 25fa of the Dutch Copyright Act, indicated by the "Taverne" license above, 


\title{
Cholinergic modulation of auditory processing, sensory gating and novelty detection in human participants
}

\author{
Inge Klinkenberg • Arjan Blokland • Wim J. Riedel • Anke Sambeth
}

Received: 25 November 2011 / Accepted: 5 September 2012 /Published online: 3 October 2012

(C) Springer-Verlag 2012

\begin{abstract}
Rationale Suppression of redundant auditory information and facilitation of deviant, novel, or salient sounds can be assessed with paired-click and oddball tasks, respectively. Electrophysiological correlates of perturbed auditory processing found in these paradigms are likely to be a trait marker or candidate endophenotype for schizophrenia.

Objective This is the first study to investigate the effects of the muscarinic M1 antagonist biperiden and the cholinesterase inhibitor rivastigmine on auditory-evoked potentials (AEPs), sensory gating, and mismatch negativity (MMN) in young, healthy volunteers.

Results Biperiden increased P50 amplitude and prolonged N100 and P200 latency in the paired-click task but did not affect sensory gating. Rivastigmine was able to reverse the effects of biperiden on N100 and P200 latency. Biperiden increased P50 latency in the novelty oddball task, which was reversed by concurrent administration of rivastigmine. Rivastigmine shortened N100 latency and enhanced P3a amplitude in the novelty oddball paradigm, both of which were reversed by biperiden.

Conclusion The muscarinic M1 receptor appears to be involved in preattentive processing of auditory information in the paired-click task. Additional effects of biperiden versus rivastigmine were reversed by a combination treatment, which renders attribution of these findings to muscarinic M1 versus muscarinic M2-M5 or nicotinic receptors much more difficult. It remains to be seen whether the effects of cholinergic drugs on AEPs are specifically related to the abnormalities found in schizophrenia. Alternatively, aberrant
\end{abstract}

I. Klinkenberg $(\bowtie) \cdot$ A. Blokland $\cdot$ W. J. Riedel $\cdot$ A. Sambeth Faculty of Psychology and Neuroscience,

Department of Neuropsychology and Psychopharmacology,

Maastricht University,

P.O. Box 616, 6200 MD Maastricht, The Netherlands

e-mail: i.klinkenberg@alumni.maastrichtuniversity.nl auditory processing could also be indicative of a general disturbance in neural functioning shared by several neuropsychiatric disorders and/or neurodegenerative changes seen in aging.

Keywords Schizophrenia $\cdot$ Event-related potentials . Cognition · Attention · Acetylcholine · Muscarinic M1 . Sensory gating $\cdot$ Mismatch negativity

\section{Introduction}

Suppression of redundant auditory information, i.e., "gatingout", and facilitation of deviant, novel, or salient sounds, i.e., "gating-in", can be assessed with electrophysiological paradigms such as paired-click and oddball tasks, respectively. Both of these make use of the automatic processing of auditory stimuli in the absence of effortful attention, yielding socalled auditory-evoked potentials (AEPs) typically consisting of a P50-N100-P200 complex (e.g., Javitt et al. 2008; Leiser et al. 2011; Lijffijt et al. 2009). It has been suggested by Boutros et al. (2004) that these three components reflect distinct stages of information processing, i.e., P50, preattentive; N100, early attentive; and P200, late attentive mechanisms. In paired-click paradigms, participants are presented with two identical auditory stimuli temporally spaced $500 \mathrm{~ms}$ apart (Boutros et al. 2004). The amplitude of the P50 peak to the first click, also termed S1 or conditioning stimulus, is usually larger than that to the second click, called S2 or the test stimulus (Oranje et al. 2006); this is indicative of inhibition of redundant input and intact sensory gating (BrockhausDumke et al. 2008). Oddball paradigms can elicit several AEP components in addition to the P50-N100-P200 complex, such as the mismatch negativity (MMN) and P3a. In these tasks, infrequent deviant and/or novel sounds are embedded 
within a string of repetitive standard tones (Garrido et al. 2009; Näätänen et al. 2004; Pekkonen et al. 2005).

In schizophrenia, mechanisms of sensory gating and novelty detection are disrupted, resulting in an overflow of sensory input and associated symptomatology such as cognitive fragmentation and thought disorder (Ford 1999; McGhie and Chapman 1961). Impaired sensory filtering mechanisms in schizophrenia patients have been linked to several electrophysiological findings, such as deficient sensory gating of P50, N100, and P200 components in pairedclick paradigms (Boutros et al. 2004; Brockhaus-Dumke et al. 2008; Erwin et al. 1998; Olincy et al. 2010), and reduced amplitudes and delayed latencies of N100, P300, and MMN components but not the P200 in novelty oddball tasks (Bramon et al. 2004a; Bramon et al. 2004b; Jeon and Polich 2001; Laurent et al. 1999; Simons et al. 2011; Souza et al. 1995; Umbricht and Krljes 2005). ${ }^{1}$ Of note, changes in auditory processing are not specific for schizophrenia, as these have also been reported in aging and age-related disorders (e.g., Cancelli et al. 2006; Gmehlin et al. 2011; Golob et al. 2007; Juckel et al. 2008; Kisley et al. 2005; Schiff et al. 2008; Thomas et al. 2010).

Besides the strong involvement of the dopaminergic and glutaminergic neurotransmitter systems in schizophrenia, alterations in muscarinic M1 signaling also appear to underlie the disorder (e.g., Sarter et al. 2012). For example, administration of the muscarinic M1 antagonists biperiden or procyclidine has been shown to increase positive symptoms (Johnstone et al. 1983; Tandon et al. 1990), yet reduce negative symptoms in schizophrenia patients (Tandon et al. 1992). In addition, cholinesterase inhibitors and muscarinic M1 agonists have been found to modestly improve various measures of cognitive function, particularly attention and short-term memory (Bora et al. 2005; Buchanan et al. 2008; Buchanan et al. 2002; Friedman 2004; Lee et al. 2007; Risch et al. 2007; Schubert et al. 2006; Shekhar et al. 2008; but see Friedman et al. 2002).

Despite a vast amount of research on the role of nicotinic receptors (e.g., Adler et al. 1998; Pritchard et al. 2004), data on the role of muscarinic neurotransmission in human AEPs is relatively limited. For instance, using an active oddball paradigm, N100, P200, and P300, but not P50 amplitudes were found to be decreased after administration of the nonselective muscarinic antagonist scopolamine (Curran et al. 1998). Moreover, scopolamine has been shown to delay P50 and N100, but not P200 or MMN latencies in healthy elderly participants presented with a passive oddball paradigm (Pekkonen et al. 2005). A few studies have looked into

\footnotetext{
${ }^{1}$ The existing literature on P300 abnormalities in schizophrenia has focused mostly on the P3b subcomponent, although a limited number of studies have also reported reduced P3a amplitudes (Grillon et al. 1990; Turetsky et al. 2000).
}

the effects of cholinesterase inhibitors on AEPs. For instance, using a task in which trains of auditory clicks were presented, a reduction in P50 amplitude by scopolamine was shown to be reversible by administration of physostigmine (Buchwald et al. 1991). Furthermore, in a study by Buchanan et al. (2002), donepezil was found to modestly improve P50 suppression in schizophrenia patients. Lastly, using an active oddball paradigm, physostigmine was able to partially counteract the effects of scopolamine on the P300 component (i.e., reduced amplitude and delayed latency: Meador et al. 1987; Meador et al. 1988). Given the involvement of the muscarinic M1 receptor in schizophrenia, it would be interesting to find out whether drugs that target this receptor would affect AEP components.

The current study is the first to assess the effects of the muscarinic M1 antagonist biperiden and the cholinesterase inhibitor rivastigmine on AEPs and sensory gating in young, healthy volunteers. Using a paired-click task and a passive novelty oddball paradigm, we first looked at general auditory processing (i.e., P50-N10-P200 complex). In addition, for the paired-click task, we also determined P50 gating, whereas for the novelty oddball task, we assessed novelty processing (i.e., by $\mathrm{P} 3 \mathrm{a}$ and $\mathrm{MMN}$ components).

We hypothesized that after biperiden, AEPs would be affected in a manner similar to scopolamine. In line with the findings of Buchwald et al. (1991), we expected a reduction in P50 amplitude after biperiden and reversal by rivastigmine. Specifically, given the cognition-deteriorating effects of biperiden (e.g., Wezenberg et al. 2005), we anticipated that biperiden would disrupt P50 gating by lowering P50 amplitude of the S1 stimulus and that rivastigmine would be able to counteract this effect. Effects of muscarinic antagonists and cholinesterase inhibitors on P50 latency and the N100 and P200 components have not been assessed previously in a paired-click task. Therefore, we did not have any specific hypotheses regarding effects of biperiden or rivastigmine on P50 latency, and the N100 and P200 peaks.

For the novelty oddball task, we anticipated no change in P50 amplitude after biperiden or rivastigmine, which is in line with findings of muscarinic drugs in the literature (Curran et al. 1998; Pekkonen et al. 2005). As scopolamine has been shown to increase P50 latency in passive novelty oddball paradigms, we expected the same effect after biperiden. After scopolamine, N100 amplitude has been shown to be unaffected, whereas N100 latency has been found to be increased in a passive novelty oddball paradigm (Pekkonen et al. 2005). Therefore, we hypothesized that biperiden would have the same effects. Scopolamine has been shown to leave the P200 component unchanged in passive novelty oddball paradigms (Pekkonen et al. 2005), and we hypothesized that biperiden would behave similarly.

In agreement with findings on scopolamine in novelty oddball paradigms (Pekkonen et al. 2005), we anticipated 
that biperiden would not influence MMN amplitude or latency. Moreover, we hypothesized that biperiden would decrease P3a amplitude, which would be reversed by concurrent rivastigmine administration (in line with the findings of Boutros et al. 2004; Meador et al. 1987). It is currently unknown whether cholinesterase inhibitors affect P50, N100, P200, or MMN components in novelty oddball paradigms. However, given the cognition-enhancing effects of cholinesterase inhibitors (e.g., Farlow 2003; Rosler et al. 1999), we expected that MMN amplitude would be increased after rivastigmine. We did not have any specific hypotheses regarding effects of rivastigmine on the P50 N100-P200 complex.

\section{Methods}

\section{Participants}

Nineteen (seven male, 12 female; mean age of 21.89 years $(\mathrm{SD}=2.8$, range $=18-28))$ healthy volunteers were recruited from Maastricht University through poster advertisements. Participants had a body mass index between 18.5 and 30 . They received a medical screening before testing, consisting of a medical questionnaire, physical examination, measurement of blood pressure and pulse rate, blood samples for hematology and biochemistry, urine samples for drug screen and pregnancy test, and a resting electrocardiogram. Exclusion criteria were past or current psychiatric, neurological, cardiac, gastrointestinal, hematological, hepatic, pulmonary, or renal illness; pregnancy; lactation; excessive alcohol consumption (intake of more than 20 glasses per week); use of any medication other than oral contraceptives; having a first-degree relative with a current or past psychiatric disorder; and presence of other deficits that could be expected to influence performance. All subjects gave a signed informed consent before inclusion and were financially rewarded for their participation. The study was approved by the Medical Ethics Committee of Maastricht University and, therefore, performed in accordance with the ethical standards laid down in the 1964 Declaration of Helsinki.

\section{Study design and procedures}

The study was conducted according to a double-blind, placebo-controlled cross-over design. Subjects were not allowed to use any psychoactive medication within 5 days before drug intake. One hour before testing, the participants were asked to fill out questionnaires on mood and physical complaints (see below). Immediately afterwards, they were given two capsules for oral intake. These included either: (1) placebo, i.e., two placebo capsules; (2) biperiden, i.e., one biperiden hydrochloride capsule of $2 \mathrm{mg}$ (Akineton ${ }^{\circledR}$, instant release) and one placebo capsule; (3) rivastigmine, i.e., one rivastigmine tartrate capsule of $3 \mathrm{mg}\left(\right.$ Exelon $\left.^{\circledR}\right)$ and one placebo capsule; or (4) a combination treatment of biperiden and rivastigmine, i.e., one biperiden hydrochloride capsule of $2 \mathrm{mg}$ (Akineton ${ }^{\circledR}$, instant release) and one rivastigmine tartrate capsule of $3 \mathrm{mg}\left(\right.$ Exelon $\left.^{\circledR}\right)$.

Participants were provided lunch immediately afterwards: this was done in order to reduce the chances of participants developing any side effects due to biperiden and rivastigmine intake. Lunch consisted of a theine-free tea and bread with savory or sweet bread toppings. Next, EEG electrodes and a cap were placed. Exactly 60 min after drug intake, behavioral testing and EEG recording started. After about $1 \mathrm{~h}$ of testing, the participant had a short break, in which he or she was asked to fill out the same questionnaires again. The test session finished about $3 \mathrm{~h}$ after drug intake. Participants underwent four testing days and on each testing day, one of the four treatments was administered. To prevent order effects, participants were randomly assigned to one of 20 balanced treatment sequences. All treatments were administered with a washout period of 7 days.

\section{Drug treatment}

Biperiden is a muscarinic M1 antagonist approved for the adjunctive treatment of Parkinson's disease and for extrapyramidal symptoms related to antipsychotic drug therapy (e.g., Ogino et al. 2011). It has about tenfold higher affinity for M1 as compared to M2-M5 receptors and it is, thus, the most selective M1 antagonist available for use in human participants (Bolden et al. 1992; Katayama et al. 1990). In humans, peak plasma concentrations are reached around 1$2 \mathrm{~h}$ after a single dose administration followed by a rapid initial decline to values around 12 of the peak values at $6 \mathrm{~h}$ after intake. This is subsequently followed by a slow terminal elimination phase at $48 \mathrm{~h}$ (Hollmann et al. 1984; Hollmann et al. 1987). The most common side effects of biperiden on the central nervous system are drowsiness, vertigo, headache, and dizziness. Peripheral side effects consist of blurred vision, dry mouth, impaired sweating, abdominal discomfort, and obstipation. Biperiden also causes some degree of mydriasis (e.g., Mintzer and Burns 2000).

Rivastigmine is an intermediate-acting cholinesterase inhibitor approved for symptomatic treatment of mild to moderate Alzheimer's disease (Jann et al. 2002; Lefevre et al. 2008). It stimulates cholinergic neurotransmission by preventing the breakdown of acetylcholine in the synaptic cleft. Specifically, it inhibits the enzymes acetylcholinesterase and butyrylcholinesterase which metabolize acetylcholine (Jann et al. 2002). Peak plasma concentrations are reached around 50-70 min and the half-life is around 60-90 min (Farlow 2003; Jann et al. 2002). The duration of cholinesterase 
inhibition is suggested to be around $8-10 \mathrm{~h}$ after drug intake. The most common side effects seen in association with the use of rivastigmine occur in the gastrointestinal tract and central nervous system; these include abdominal pain, nausea, vomiting, diarrhea, headache, and dizziness. Dose conditions of biperiden and rivastigmine were chosen based on the study by Wezenberg et al. (2005). Both drugs were purchased, blinded, and labeled by the pharmacy of the University Hospital Maastricht according to relevant GMP guidelines.

\section{Questionnaires}

To assess subjective mood changes, we used the Profile of Mood States (POMS: McNair et al. 1971) and the Bond and Lader mood scale (Bond and Lader 1974). Physical or mental complaints were assessed with a self-report questionnaire consisting of 31 possible complaints to be rated on a four-point scale; a score of zero indicates that the participant is not experiencing the complaint, and a score of three means he or she is experiencing it a great deal. For all three questionnaires, a difference score of $T_{1}(1 \mathrm{~h}$ after drug intake) $-T_{0}$ (baseline, before drug intake) was calculated per subscale for each participant and used for analysis.

\section{Paired-click paradigm}

The paired-click task was used as an electrophysiological technique to assess sensory gating mechanisms (Adler et al. 1982). Two identical 1,000-Hz clicks (S1 and S2) were binaurally presented via loudspeakers. The duration of each click was $4 \mathrm{~ms}$ with a sound intensity of $60 \mathrm{~dB}$. A short interstimulus interval (ISI) of $500 \mathrm{~ms}$ was used, as this ISI has been shown to provide maximum differentiation between the sensory gating capacities of healthy participants and schizophrenia patients (Nagamoto et al. 1989; Oranje et al. 2006). The pairs were presented in a random intertrial interval of 6-10 s, in order to allow neuronal recovery (Zouridakis and Boutros 1992). During each session, 75 pairs of clicks were presented. Participants viewed a silent animated movie while listening to the paired clicks. No behavioral measures were recorded during the paired-click task, as it is generally used to assess automatic/passive auditory information processing.

\section{Novelty oddball paradigm}

The novelty oddball task was used as an assessment of involuntary attention processes such as the MMN. Three types of auditory stimuli were presented, consisting of frequent standard, infrequent deviant, and infrequent novel stimuli. The standard and deviant stimuli were $750-\mathrm{Hz}$ and $500-\mathrm{Hz}$ tones, each with two upper harmonic components
(1,500 and 2,250, and 1,000 and 1,500 Hz, respectively). The intensity of the first and second harmonic components was decreased compared to the fundamental by 3 and $6 \mathrm{~dB}$, respectively. Novel stimuli consisted of three stimulus categories of 20 different auditory stimuli, namely, animal, human, and mechanical sounds. The deviant and novel stimuli were each presented in $12.5 \%$ of the trials. All sounds had a duration of $300 \mathrm{~ms}$ with $10 \mathrm{~ms}$ rise and fall times. The tones were presented with a $1,000 \mathrm{~ms}$ stimulusonset asynchrony and equal intensities. Participants viewed a silent animated movie while listening to the auditory stimuli. No behavioral measures were recorded during this task, as we wanted to assess automatic/passive auditory information processing.

Of note, an active version of the novelty oddball task, which requires participants to give a behavioral response to the deviant stimuli, is also employed in studies on auditory processing (e.g., Hall et al. 2006). Active oddball paradigms generally induce a parietal P3b reflecting context updating/ working memory function instead of a frontocentral P3a peak reflecting novelty/attentional processes (Comerchero and Polich 1999; Donchin 1981). Moreover, a MMN component is generated only if a passive novelty oddball paradigm is employed (e.g., Hall et al. 2006). Because of the role of acetylcholine in in vivo novelty processing (e.g., Miranda et al. 2000), we chose to use a passive novelty oddball paradigm instead of an active one.

\section{EEG acquisition}

For the EEG recording, the NeuroScan SynAmps system was used, with sample rate set at 1,000 Hz. Data were filtered between 0.05 and $100 \mathrm{~Hz}$. EEG was recorded from 32 electrodes placed on the scalp using an elastic cap (ElectroCap International, United States) and positioned according to the 10-20 system (Jasper 1958). The horizontal electrooculogram (HEOG) was measured with two electrodes placed on the outer canthus of the left and right eyes, and two electrodes placed below and above the center of the left eye recorded the vertical electrooculogram (VEOG). Two electrodes behind the ears served as reference electrodes. Before placing the electrodes, all locations were cleaned with alcohol and gently scrubbed with a gel, to ensure good conduction of the signal. Impedance was kept below 5 $\Omega$. During the EEG recordings, the participants were sitting in an electrically shielded and sound-attenuated room with the lights dimmed.

In total, we recorded and analyzed EEG from 32 electrodes, but we only included the data of the $\mathrm{Fz}, \mathrm{FCz}$, and $\mathrm{Cz}$ electrode channels in our final statistical analysis. In the literature, the $\mathrm{Cz}$ electrode is usually taken for measurement of sensory gating (e.g., Boutros et al. 2004). However, since the prefrontal cortex is also involved in sensory gating 
(Grunwald et al. 2003; Williams et al. 2011), we chose to also include the $\mathrm{Fz}$ and $\mathrm{FCz}$ electrode channels. As for the novelty oddball task, we were mainly interested in the novelty $\mathrm{P} 3 \mathrm{a}$, which is a frontocentral component (Comerchero and Polich 1999; Donchin 1981). Hence, the Fz, FCz, and $\mathrm{Cz}$ electrode channels were the obvious choice and in accordance with other studies evaluating the same ERP components in these paradigms. Of note, the participants were presented with a test battery containing additional paradigms besides the paired-click and novelty oddball task. We chose to measure EEG from a total of 32 electrodes because different paradigms would elicit different ERPs, each with a different scalp distribution. Thus, electrode channels other than the Fz, FCz, and $\mathrm{Cz}$ would be employed for the ERP analysis of these additional paradigms.

\section{EEG analysis}

All EEG data was analyzed with Vision Analyzer 2.0. Before data analysis, the EEG data were visually inspected offline to check for artefacts. The EEG signal was filtered offline with a high-pass filter set at $1 \mathrm{~Hz}$ (12 dB slope) and a low-pass filter set at $30 \mathrm{~Hz}$ (12 dB slope). Eye movement artefacts were filtered out of the EEG using the data of the VEOG channel and the method developed by Semlitsch et al. (1986). This way, every participant had about the same number of artifactfree trials which were combined into the AEP averages.

In case of the paired-click task, we decided to segment the EEG according to click pairs instead of separately for each stimulus. Thus, the EEG epochs were set from $100 \mathrm{~ms}$ prior to $\mathrm{S} 1$ onset to $1,000 \mathrm{~ms}$ after onset. One segment included both $\mathrm{S} 1$ and S2, using the $100 \mathrm{~ms}$ preceding the first click in the stimulus pair as baseline. Segmenting the data for S1 and S2 separately would have implied using the $100 \mathrm{~ms}$ preceding S2 as a baseline for this stimulus. However, at this point, the EEG signal had not yet returned to its default value, which would have skewed the baseline correction used for S2. After automatic artefact rejection, averages were calculated. Based on the grand averages, we determined the position of the P50, N100, and P200 peaks for S1 and S2. Peak amplitudes were calculated and latencies were computed based on when the peak was reached. Of note, since we chose to analyze S1 and S2 within the same segment, the peaks for S2 were actually P550, N600, and P700. Please see Table 1 for the time windows chosen for the paired-click peak detection.

For the novelty oddball data, the EEG epochs were set from $100 \mathrm{~ms}$ prior to stimulus onset to $900 \mathrm{~ms}$ after onset, using the $100 \mathrm{~ms}$ prestimulus as baseline. After automatic artefact rejection, averages were calculated for each stimulus separately (standards, deviants, and novels). Based on the grand averages, we determined the position of the P50, N100, and P200 peaks for the standard, deviant, and novel
Table 1 Time windows (in ms) used for AEP analyses of the pairedclick data

\begin{tabular}{llll}
\hline $\begin{array}{l}\text { Stimulus } \\
\text { type }\end{array}$ & Peaks & & \\
\cline { 2 - 4 } & $\begin{array}{l}\text { Preattentive: } \\
\text { P50 }\end{array}$ & $\begin{array}{l}\text { Early attentive: } \\
\text { N100 }\end{array}$ & $\begin{array}{l}\text { Late attentive: } \\
\text { P200 }\end{array}$ \\
\hline S1 & $20-90$ & $70-150$ & $150-240$ \\
S2 & $520-590$ & $570-650$ & $650-740$ \\
\hline
\end{tabular}

stimuli. Moreover, two difference waves were calculated by subtracting the response to the standard from the deviant and novel stimuli. For these difference waves, we determined the position of the MMN and P3a peaks. Peak amplitudes were calculated and latencies were computed based on when the peak was reached. Please see Table 2 for the time windows chosen for novelty oddball peak detection.

\section{Statistics}

All data were analyzed using SPSS. To determine possible treatment effects on general auditory processing (i.e., P50 N100-P200 complex) of the paired-click task, AEP data were analyzed by several repeated measures ANOVAs with Drug (four levels: placebo, biperiden, rivastigmine, and the combination treatment), Stimulus (two levels: $\mathrm{S} 1$ and $\mathrm{S} 2$ ), and Electrode (three levels: $\mathrm{Fz}, \mathrm{FCz}$, and $\mathrm{Cz}$ ) as withinsubject variables. Effects on P50 suppression would be reflected by a significant Treatment * Stimulus interaction. Next, we wanted to see if our treatment conditions would affect general auditory processing (i.e., P50-N100-P200 complex) in the novelty oddball task. Therefore, we ran repeated measures ANOVAs on the AEP data of the standard stimuli, with Drug (four levels: placebo, biperiden, rivastigmine, and the combination) and Electrode (three levels: $\mathrm{Fz}, \mathrm{FCz}$, and $\mathrm{Cz}$ ) as within-subject variables. Next, we sought to determine if our treatment conditions influenced novelty processing (i.e., difference scores of deviant standard and novel - standard waves, also see previous section). Therefore, we performed several repeated measures ANOVAs with Drug (four levels: placebo, biperiden, rivastigmine, and the combination), Stimulus (two levels: Diff $_{\text {deviant }}$ and Diff ${ }_{\text {novel }}$ ), and Electrode (three levels: Fz, $\mathrm{FCz}$, and $\mathrm{Cz}$ ) as within-subject variables. For the AEP data, all analyses were done separately for amplitude and latency, and for each of the AEP components. Most of the repeated measures analyses yielded significant interactions with the variables Electrode and Stimulus. In these cases, we performed additional ANOVAs split for each level of Electrode in order to examine simple effects. For reasons of brevity, we decided to only discuss these simple effects analyses in Results and to leave out the overall analysis. If one of the 
Table 2 Time windows (in ms) used for AEP analyses of the novelty oddball data

\begin{tabular}{llll}
\hline Stimulus type & Peaks & & \\
& Preattentive: P50 & Early attentive: N100 & Late attentive: P200 \\
Standards & $20-120$ & $90-150$ & $140-240$ \\
Deviants & $20-120$ & $90-150$ & $180-260$ \\
Novels & $20-120$ & $90-150$ & $180-260$ \\
& & & \\
Stimulus type & Peaks & & \\
& Change detection: MMN & Novelty processing: P3a & \\
Dev-Stand & $110-170$ & $170-300$ & \\
Nov-Stand & $110-170$ & $170-300$ & \\
\hline
\end{tabular}

Dev-Stand difference wave of the deviant versus the standard stimuli, $M M N$ mismatch negativity, Nov-Stand difference wave of the novel versus the standard stimuli overall repeated measures ANOVA did not yield a significant interaction term or if a Treatment*Stimulus interaction was present, this is stated clearly in Results. For all analyses, we used $\alpha=0.05$. Post hoc analysis was performed with a Least Significant Difference (LSD) test. We chose to only compare the data of the treatment conditions with placebo, so per analysis, a total of three post hoc comparisons were made.

The questionnaire data were analyzed by repeated measures ANOVAs with Drug (four levels: placebo, biperiden, rivastigmine, and the combination treatment), as withinsubject variable. These analyses were done separately for each subscale. Post hoc analysis was performed with a LSD test. We chose to only compare the data of the treatment conditions with placebo, so per analysis, a total of three post hoc comparisons were made. The POMS had five subscales, whereas for the Bond and Lader, we only analyzed the best validated subscale: alert-drowsy. For the self-report questionnaire, we only analyzed those side effects which would be expected after biperiden and/or rivastigmine intake.

\section{Results}

Four participants dropped out prematurely due to side effects of the drugs, leaving a total of 15 participants. Two participants withdrew immediately after the first testing session. They had received biperiden and rivastigmine, respectively. The other two participants resigned after three testing sessions. One person got first the combination treatment, then biperiden, and lastly rivastigmine, whereas the other had received the combination treatment, rivastigmine, and placebo, respectively. In sum, this indicates that especially rivastigmine was prone to induce participant dropout due to side effects.

Treatment effects on general auditory processing and sensory gating in the paired-click task

Figure 1 shows the $\mathrm{S} 1$ and S2 AEP responses of the placebo condition, while Figs. 2 and 3 display the effects of the treatment and stimulus conditions on P50 amplitude and N100 latency in the paired-click task, respectively. We performed repeated measures ANOVAs to determine the effects of biperiden and rivastigmine on general processing (i.e., P50 N100-P200 complex) and P50 gating in the paired-click task.

We first wanted to determine whether our Treatment conditions would affect preattentive processing in the paired-click paradigm, as assessed by the P50 component. We anticipated that biperiden would disrupt P50 gating by lowering P50 amplitude of the $\mathrm{S} 1$ stimulus and that rivastigmine would be able to counteract this effect. Gating effects would be evident by a Treatment * Stimulus interaction. In the simple effects analyses of all three electrode channels (i.e., Fz, FCz, and Cz), the effect of Treatment on P50 amplitude did not vary per level of Stimulus (no Treatment $*$ Stimulus interaction effect; $F_{S}<$ 1.21 , n.s.). In other words, our Treatment conditions did not affect P50 gating. The P50 amplitude of S2 was smaller compared to that of S1 (main effect of Stimulus; $F_{S}>28.24$, $P s<0.001$ ), signifying intact sensory gating in all Treatment conditions. Furthermore, P50 amplitude was shown to be different between treatment conditions (main effect of

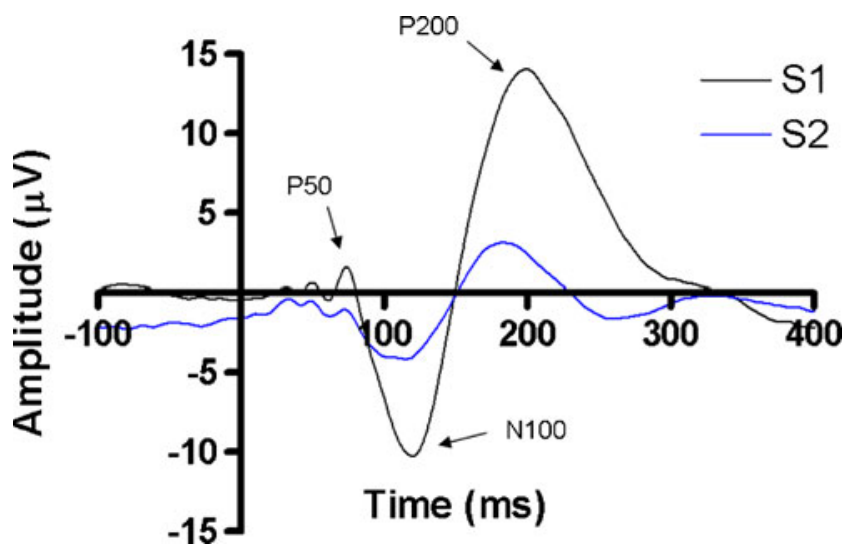

Fig. 1 AEP responses to $\mathrm{S} 1$ and $\mathrm{S} 2$ of the paired-click task in the placebo condition (shown here: $\mathrm{Cz}$ electrode). The amplitude and latency of the P50, N100, and P200 peaks were smaller for S2 compared to $\mathrm{S} 1(P S<0.05)$. There was intact sensory gating in the placebo condition, reflected by $\mathrm{P} 50_{\mathrm{S} 1}>\mathrm{P} 50_{\mathrm{S} 2}$ 
Fig. 2 Effects of the treatment and stimulus conditions on P50 amplitude of the paired-click task (shown here: Fz electrode, means + SEM, $* P s<0.05$, $* * * P s<0.001)$. P50 amplitude was larger after biperiden $(P S<0.01)$ and the combination treatment $(P s<0.05)$ compared to placebo. There was no Treatment * Stimulus interaction and, therefore, no effect on sensory gating

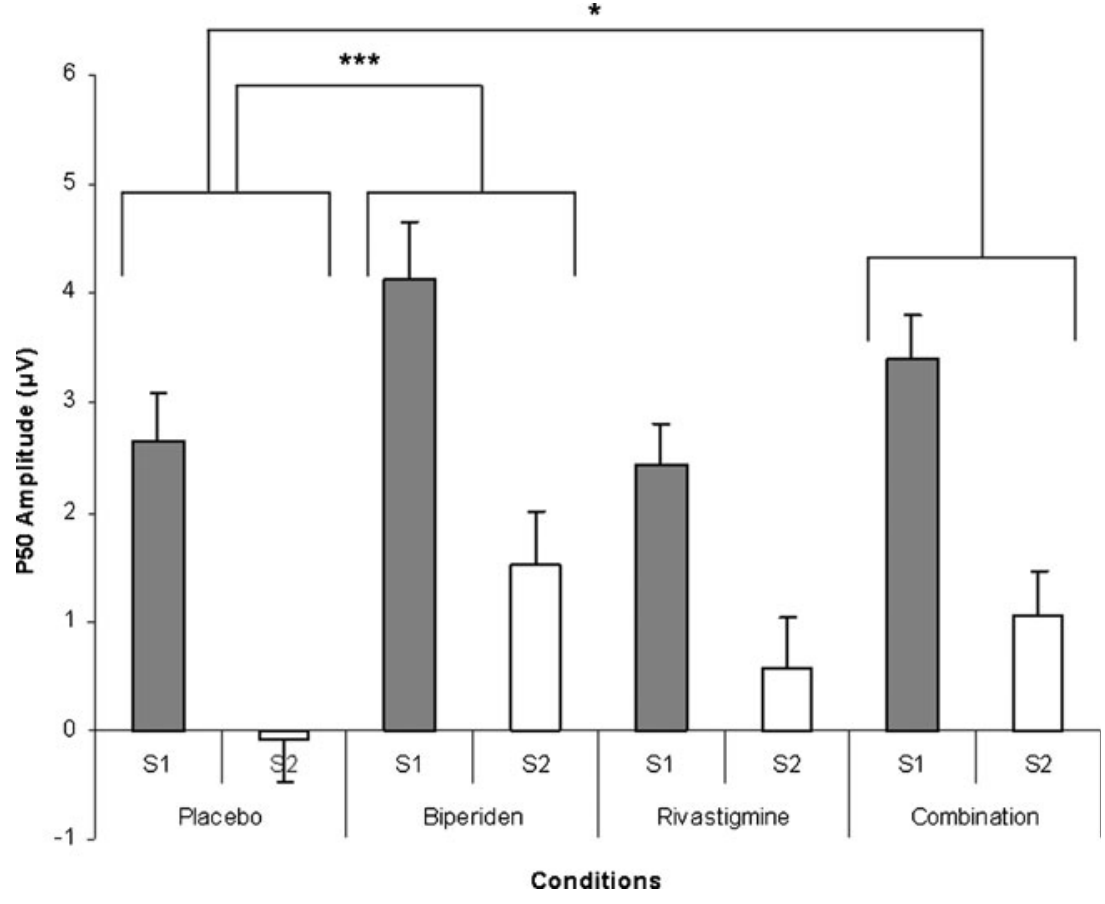

Treatment; $F_{S}>4.75, P_{S}<0.01$ ); post hoc analysis indicated that P50 amplitude was larger after biperiden $\left(P_{S}<0.01\right)$ and the combination treatment $\left(P_{S}<0.05\right)$ compared to placebo. As there was no Treatment * Stimulus interaction, biperiden and the combination conditions increased P50 amplitude similarly for both S1 and S2.

Given the lack of reports on effects of cholinergic drugs on P50 latency in paired-click tasks in the literature, we did not have any specific hypotheses regarding Treatment effects on
P50 latency. In the simple effects analysis of the Fz electrode data, there were no interactions or main effects on P50 latency $\left(F_{S}<0.68\right.$, n.s.). For the analyses of the $\mathrm{FCz}$ and $\mathrm{Cz}$ electrodes, the effect of Treatment did not vary per level of Stimulus (no Treatment $*$ Stimulus interaction effect; $F_{S}<1.90$, n.s.). P50 latency of S2 occurred earlier compared to the P50 latency of $\mathrm{S} 1$ (main effect of Stimulus; $F_{S}>4.67, P_{S}<$ 0.05 ), yet Treatment did not influence P50 latency on $\mathrm{FCz}$ and $\mathrm{Cz}$ (no main effect of Treatment; $F_{S}<2.61$, n.s.).
Fig. 3 Effects of the treatment and stimulus conditions on N100 latency of the paired-click task (shown here: Fz electrode, means $+\mathrm{SEM}, * P<0.05)$. N100 latency was larger after biperiden compared to placebo $(P s<0.05)$; this effect was reversed by concurrent administration of rivastigmine (i.e., after the combination treatment, N100 latency was statistically similar to placebo)

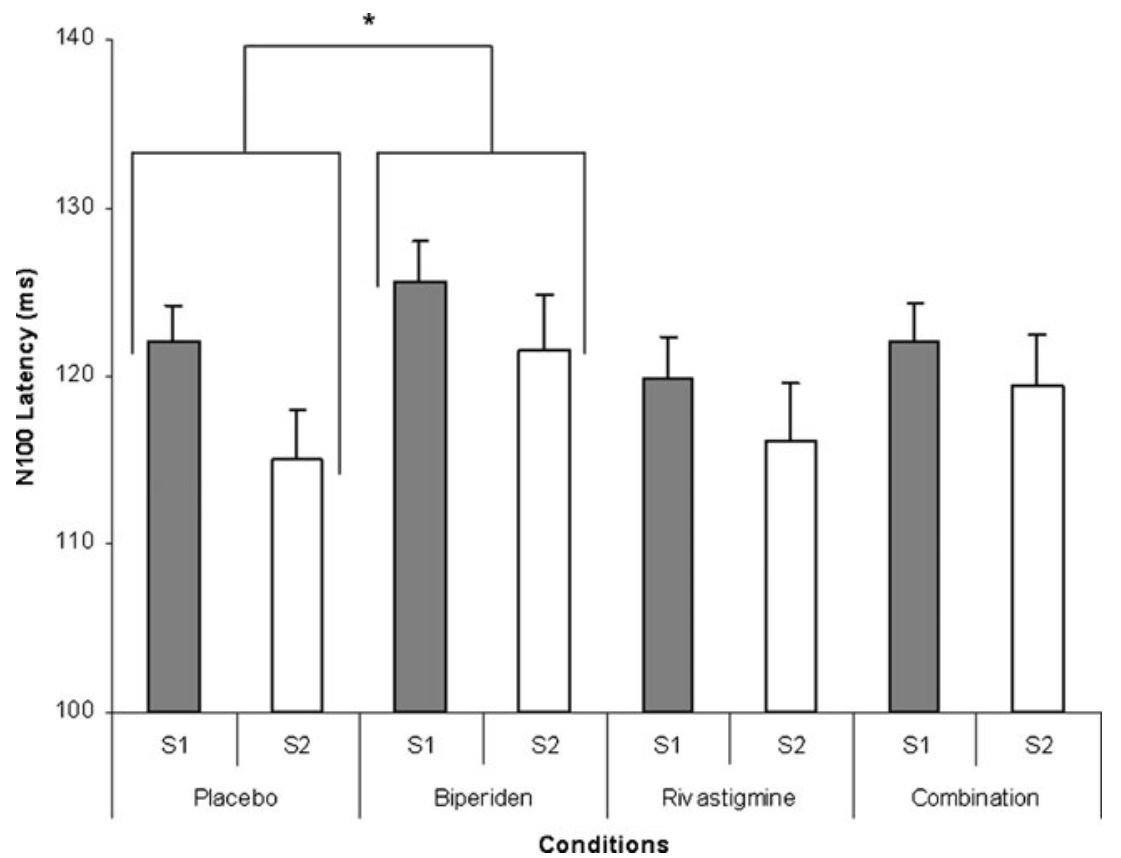


Next, we wanted to see whether there would be any effects of our cholinergic drugs on early attentive processing in the paired-click task, as measured by the N100. We did not have any specific hypotheses regarding Treatment effects on N100 amplitude or latency, given the lack of reports in the literature. In the simple effects analyses of all three electrode channels (i.e., Fz, $\mathrm{FCz}$, and $\mathrm{Cz}$ ), the effect of Treatment on N100 amplitude did not vary per level of Stimulus (no Treatment * Stimulus interaction effect; $F s<0.50$, n.s.). The N100 amplitude of S2 was smaller compared to that of S1 (main effect of Stimulus; $F_{S}>89.76, P_{S}<0.001$ ), yet Treatment did not influence N100 amplitude (no main effect of Treatment; $F_{S}<2.59$, n.s.).

In the simple effects analyses of all three electrode channels (i.e., $\mathrm{Fz}, \mathrm{FCz}$, and $\mathrm{Cz}$ ), the effect of Treatment on N100 latency did not vary per level of Stimulus (no Treatment $*$ Stimulus interaction effect; $F s<1.79$, n.s.). The N100 peak of S2 occurred earlier compared to the $\mathrm{N} 100$ of $\mathrm{S} 1$ for $\mathrm{Fz}, \mathrm{FCz}$, and $\mathrm{Cz}$ (main effect of Stimulus; $F(1,18)=5.48, P<0.05)$. Moreover, in the simple effects analysis of the Fz electrode, N100 latency was shown to be different between treatment conditions (main effect of Treatment; $F_{S}>3.16, P_{S}<0.05$ ); post hoc analysis showed that the N100 occurred later after biperiden compared to placebo $(P<0.05)$. For the $\mathrm{FCz}$ and $\mathrm{Cz}$ electrodes, Treatment did not influence N100 latency (no main effect of Treatment; $F_{S}<2.70$, n.s.).

We also sought to determine whether there would be any effects of our cholinergic drugs on late attentive processing in the paired-click task, as measured by the P200. Given the lack of reports in the literature, we did not have any specific hypotheses regarding Treatment effects on P200 amplitude or latency. In the simple effects analyses of all three electrode channels (i.e., $\mathrm{Fz}, \mathrm{FCz}$, and $\mathrm{Cz}$ ), the effect of Treatment on P200 amplitude did not vary per level of Stimulus (no Treatment * Stimulus interaction effect; $F_{S}<1.47$, n.s.). The P200 amplitude of S2 was smaller compared to that of S1 (main effect of Stimulus; $F_{S}>100.40, P_{S}<0.001$ ), yet
Treatment did not influence P200 amplitude for $\mathrm{Fz}, \mathrm{FCz}$, and $\mathrm{Cz}$ (no main effect of Treatment; $F_{S}<1.35$, n.s.).

In the simple effects analyses of the $\mathrm{Fz}$ and $\mathrm{FCz}$ electrode channels, the effect of Treatment on P200 latency did not vary per level of Stimulus (no Treatment * Stimulus interaction effect; $F s<1.39$, n.s.). The P200 latency of S2 was shorter compared to that of S1 (main effect of Stimulus; $F_{S}>7.71, P_{s}<0.05$ ), yet Treatment did not influence $\mathrm{P} 200$ latency at $\mathrm{Fz}$ and $\mathrm{FCz}$ (no main effect of Treatment; $F s<1.16$, n.s.). For the simple effects analysis of the $\mathrm{Cz}$ electrode, the effect of Treatment varied per level of Stimulus (Treatment * Stimulus interaction effect; $F(3,54)=3.09, P<0.05)$. Hence, we did separate repeated measures analyses per level of Stimulus. For the data of the S1 stimulus, P200 latency was shown to be different between treatment conditions (main effect of Treatment; $F(3,54)=4.23, P<0.01$ ); post hoc analysis showed that the $\mathrm{P} 200$ occurred later after biperiden $(P<0.05)$ and after the combination treatment $(P<0.05)$ compared to placebo. There were no effects in the analysis of the $\mathrm{S} 2$ data $(F(3,54)=0.50$, n.s. $)$.

Treatment effects on general auditory processing of the standard stimuli in the novelty oddball task

Figure 4 shows the AEP responses to the standard, deviant, and novel stimuli of the placebo condition, whereas Fig. 5 displays the effects of the four treatment conditions on N100 latency of the standard stimuli in the novelty oddball task. We performed repeated measures ANOVAs to determine the effects of biperiden and rivastigmine on general processing (i.e., P50-N100-P200 complex) in the novelty oddball task.

We first wanted to determine whether our Treatment conditions would affect preattentive processing in the novelty oddball paradigm, as assessed by the P50 component. We anticipated no change in P50 amplitude after biperiden. Due to the limited literature on cholinergic drugs and auditory processing, we did not have any specific hypotheses regarding effects of rivastigmine on the P50 peak. In the
Fig. 4 AEP responses to the standard, deviant, and novel stimuli of the novelty oddball task (shown here: $\mathrm{Cz}$ electrode). Generally, deviant and novel sounds elicited larger amplitudes than standards $\left(P_{S}<0.05\right)$

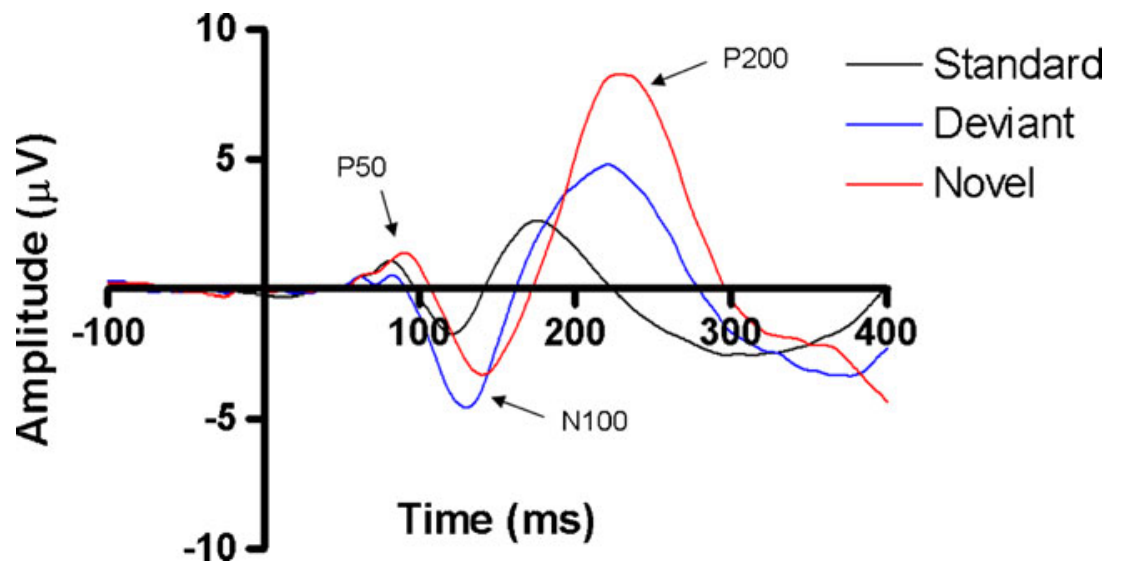


Fig. 5 Effects of the treatment conditions on N100 latency of the novelty oddball task (shown here: Fz electrode, means + SEM, $* P<0.05)$. N100 latency was shorter after rivastigmine compared to placebo $\left(P_{S}<0.05\right)$; this effect was reversed by concurrent administration of biperiden (i.e., after the combination treatment, N100 latency was statistically similar to placebo)

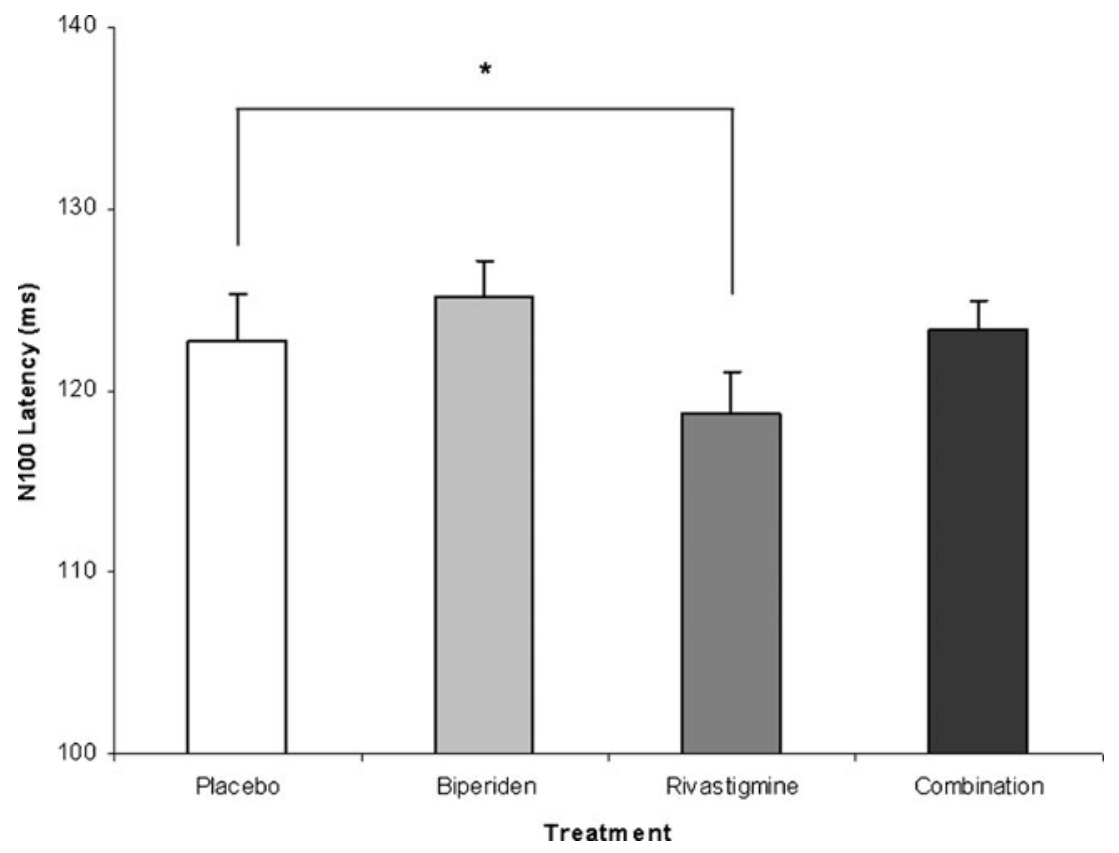

overall analysis of P50 amplitude, the effect of Treatment did not vary per level of Electrode (no Electrode * Treatment interaction effect; $F(6,108)=0.32$, n.s.). P50 amplitude was shown to differ according to treatment conditions (main effect of Treatment; $F(3,54)=5.43, P<0.01)$; however, post hoc analysis did not yield any significant results.

We expected an increase in P50 latency after biperiden. The overall analysis of P50 latency demonstrated that the effect of Treatment did not vary per level of Electrode (no Electrode * Treatment interaction effect; $F(6,108)=0.43$, n.s.). P50 latency was shown to be different between treatment conditions (main effect of Treatment; $F(3,54)=3.02$, $P<0.05)$; post hoc analysis showed that the P50 occurred later after biperiden compared to placebo $(P<0.05)$.

Next, we wanted to see whether there would be any effects of our cholinergic drugs on early attentive processing in the novelty oddball task, as measured by the N100. We hypothesized that N100 amplitude would be unaffected, whereas N100 latency would be increased after biperiden. Due to the limited literature on cholinergic drugs and auditory processing, we did not have any specific hypotheses regarding effects of rivastigmine on the N100 peak. Indeed, the repeated measures ANOVA of N100 amplitude did not yield any relevant effects $(F s<2.38$, n.s. $)$. With regards to the overall analysis of N100 latency, the effect of Treatment did not vary per level of Electrode (no Electrode * Treatment interaction effect; $F(6,108)=1.34$, n.s.). N100 latency was shown to differ according to treatment conditions (main effect of Treatment; $F(3,54)=6.83, P<0.01)$; post hoc analysis showed that the N100 occurred earlier after rivastigmine compared to placebo $(P<0.05)$.

We also sought to determine whether there would be any effects of cholinergic drugs on late attentive processing in the novelty oddball task, as measured by the P200. We anticipated that the P200 component would be unchanged after biperiden. Due to the limited literature on cholinergic drugs and auditory processing, we did not have any specific hypotheses regarding effects of rivastigmine on the P200 peak. The repeated measures analysis of P200 amplitude did not yield any relevant effects $\left(F_{S}<1.43\right.$, n.s.). The overall analysis of P200 latency demonstrated that the effect of Treatment did not vary per level of Electrode (no Electrode * Treatment interaction effect; $F(6,108)=1.20$, n.s.). P200 latency was shown to be different between treatment conditions (main effect of Treatment; $F$ $(3,54)=3.45, P<0.05)$; however, post hoc analysis did not yield any Treatment effects compared to placebo.

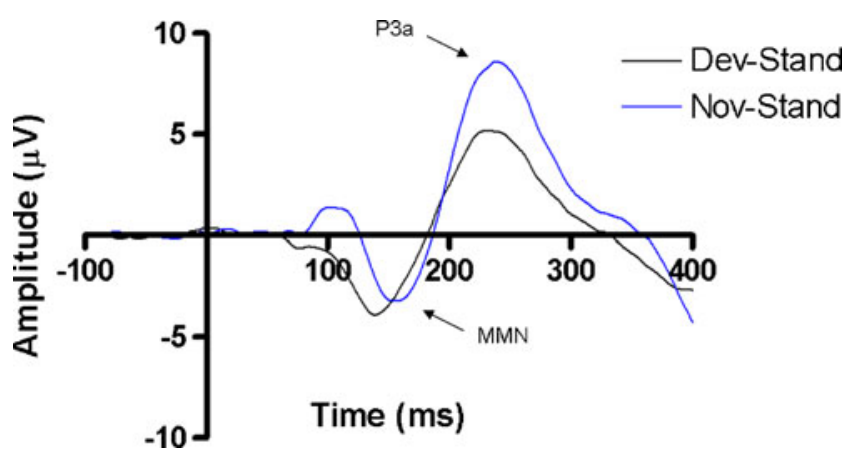

Fig. 6 Deviant-standard and novel-standard difference waves of the novelty oddball task (shown here: FCz electrode). The MMN amplitude of the novel-standard was smaller compared to that of the deviant-standard difference score (only at the Fz electrode; $P<0.05$ ). Moreover, the MMN occurred later for the novel-standard compared to that of the deviant-standard difference score $(P<0.001)$. The P3a amplitude of the novel-standard was larger compared to that of the deviant-standard difference score $\left(P_{s}<0.01\right)$. There were no effects of the difference scores on P3a latency 
Fig. 7 Effects of the treatment conditions on $\mathrm{P} 3 \mathrm{a}$ amplitude of the difference scores in the novelty oddball task (shown here: $\mathrm{Cz}$ electrode, means + SEM, $* P<0.05)$. P3a amplitude was larger after rivastigmine compared to placebo $(P s<0.05)$; this effect was reversed by concurrent administration of biperiden (i.e., after the combination treatment, $\mathrm{P} 3 \mathrm{a}$ amplitude was statistically similar to placebo)

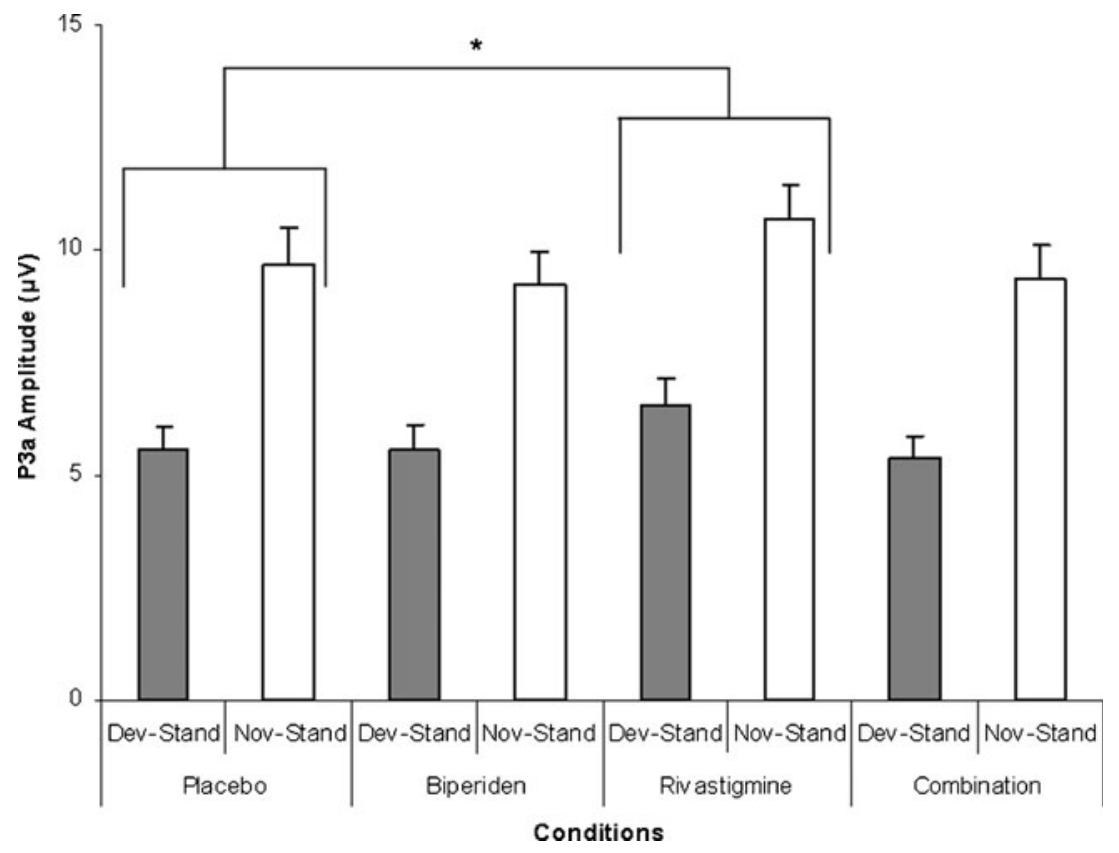

Treatment effects on novelty processing in the novelty oddball task

Figure 6 visualizes the deviant-standard and novel-standard difference waves of the novelty oddball task, while Fig. 7 shows the effects of the treatment and stimulus difference scores on P3a amplitude in the novelty oddball task. We performed repeated measures ANOVAs to determine the effects of biperiden and rivastigmine on novelty processing (i.e., MMN and P3a) in the novelty oddball task.

We anticipated that biperiden would not influence MMN amplitude or latency but did expect an increase in MMN amplitude after rivastigmine. In the simple effects analysis of the Fz electrode data, the effect of Treatment did not vary per level of Stimulus (no Stimulus * Treatment interaction effect; $F(3,54)=0.14$, n.s.). The MMN amplitude of the Diff $_{\text {novel }}$ wave was smaller compared to that of the Diff deviant wave (main effect of Stimulus; $F(1,18)=6.84, P<0.05$ ), yet Treatment did not influence MMN amplitude (no main effect of Treatment; $F(3,54)=1.20$, n.s.). The simple effects analyses of the $\mathrm{FCz}$ and $\mathrm{Cz}$ electrode channels did not yield any relevant effects on MMN amplitude $(F s<1.52$, n.s. $)$.

There were no interaction effects in the overall repeated measures analysis of MMN latency $(F s<1.50$, n.s.). The

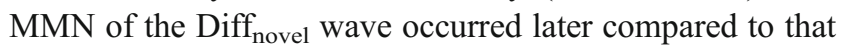
of the Diff deviant $_{\text {wave (main effect of Stimulus; } F(1,18)=}$ $30.51, P<0.001)$, yet Treatment did not influence MMN amplitude (no main effect of Treatment; $F(3,54)=0.69$, n.s.).

Next, we wanted to see whether there would be any effects of our cholinergic drugs on the P3a component in the novelty oddball task. We anticipated that biperiden would decrease P3a amplitude, which would be reversed by concurrent rivastigmine administration. The simple effects analyses of all three electrode channels (i.e., Fz, $\mathrm{FCz}$, and $\mathrm{Cz}$ ) did not yield any interaction effects on P3a amplitude $(F s<0.22$, n.s. $)$. The P3a amplitude of the Diff $_{\text {novel }}$ wave was larger compared to that of the Diff deviant $_{\text {t }}$ wave (main effect of Stimulus; $F_{S}>10.68, P_{S}<0.01$ ). Furthermore, Treatment influenced $\mathrm{P} 3 \mathrm{a}$ amplitude for $\mathrm{Fz}, \mathrm{FCz}$, and $\mathrm{Cz}$ (main effect of Treatment; $F_{S}>3.42, P_{S}<0.05$ ); however, post hoc analysis of the $\mathrm{Fz}$ and $\mathrm{FCz}$ electrodes did not yield any significant results. The post hoc analysis of the $\mathrm{Cz}$ electrode demonstrated that $\mathrm{P} 3 \mathrm{a}$ amplitude was increased after rivastigmine $(P<0.05)$. Thus, our hypothesis regarding effects of cholinergic drugs on $\mathrm{P} 3$ a amplitude was only partially confirmed.

We did not have any expectations regarding effects of cholinergic drugs on P3a latency in the novelty oddball task, given the lack of reports in the literature. In the simple effects analyses of the $\mathrm{Fz}$ and $\mathrm{Cz}$ electrode channels, there were no interactions or main effects on P3a latency $\left(F_{S}<\right.$ 2.36, n.s.). For the $\mathrm{FCz}$ electrode, the effect of treatment on P3a latency did not vary per level of Stimulus (no Stimulus * Treatment interaction effect; $F(3,54)=1.25$, n.s.). Furthermore, P3a latency was statistically similar between the Diffdeviant and Diffnovel wave (no main effect of Stimulus; $F$ $(1,18)=2.01$, n.s.). Treatment was found to affect P3a latency (main effect of Treatment; $F(3,54)=3.00, P<0.05$ ); however, post hoc analysis did not yield any significant results.

Treatment effects on questionnaires

Table 3 shows the average difference scores $\left(T_{1}-T_{0}\right)$ for the four treatment conditions on the POMS subscales. The 
Table 3 Treatment effects on the difference scores $\left(T_{1}-T_{0}\right)$ of the POMS subscales; means (+SEMs). Significance asterisks reflect Treatment effects compared to the placebo condition

POMS Profile of Mood States $* * P<0.01 ; * * * P<0.001$

\begin{tabular}{lllll} 
POMS subscales & \multicolumn{2}{l}{ Treatment conditions } & \\
\cline { 2 - 5 } & Placebo & Biperiden & Rivastigmine & Combination \\
\hline Depression-dejection & $20.26(12.77)$ & $-34.37^{* *}(10.61)$ & $-14.05(10.34)$ & $32.68(9.30)$ \\
Anger-hostility & $51.37(34.91)$ & $-14.16(11.06)$ & $-15.47(11.18)$ & $-19.58(26.50)$ \\
Fatigue-inertia & $47.84(13.80)$ & $-54.42^{* * *}(12.85)$ & $-32.53^{* *}(12.07)$ & $71.11(12.74)$ \\
Vigor-activity & $43.11(11.83)$ & $-49.47^{* *}(14.97)$ & $-28.37^{* *}(12.94)$ & $69.37(17.30)$ \\
Tension-anxiety & $3.37(8.82)$ & $0.95(11.04)$ & $-1.95(10.61)$ & $0.68(5.71)$ \\
\hline
\end{tabular}

analysis of the POMS data revealed that Treatment had an effect on the depression-dejection scale (main effect of Treatment; $F(3,54)=7.36, P<0.001)$; post hoc analysis showed that after biperiden, participants felt happier compared to placebo $(P<0.01)$. Moreover, Treatment also influenced the fatigue-inertia scale (main effect of Treatment; $F$ $(3,54)=20.59, P<0.001)$; post hoc analysis showed that participants felt less tired after biperiden $(P<0.001)$ and after rivastigmine $(P<0.01)$ compared to the placebo condition. Furthermore, Treatment also affected the vigor-activity scale (main effect of Treatment); post hoc analysis showed that participants felt less energetic after biperiden $(P<0.01)$ and after rivastigmine $(P<0.01)$ compared to the placebo condition. There were no Treatment effects on the POMS scales anger-hostility and tension-anxiety $(F s<2.09$, n.s. $)$. Treatment also did not influence the Bond and Lader Alertness scale $(F(3,54)=2.42$, n.s. $)$ nor any of the self-report scales $\left(F_{S}<2.71\right.$, n.s. $)$.

\section{Discussion}

The goal of the current study was to assess the effects of biperiden and rivastigmine on sensory gating and $\mathrm{MMN}$ in young, healthy participants. In Table 4 , an overview is given of the effects of both drugs on the various AEPs.

\section{Paired-click task}

\section{Preattentive processing: P50 amplitude was enlarged after biperiden but no reversal by rivastigmine}

For the paired-click task, both biperiden and the combination treatment enlarged the amplitude of the P50 peak (see Fig. 2). The latter is likely due to an underlying effect of biperiden and also given the fact that rivastigmine did not change the $\mathrm{P} 50$ relative to placebo. This would argue for a role of the muscarinic M1 receptor in preattentive processing. Furthermore, as the P50 amplitude of both the S1 and S2 stimuli was increased, there was no effect of biperiden on P50 gating (i.e., no interaction between Treatment and Stimulus). These results were quite unexpected in light of our hypothesis stating a disruption of sensory gating due to a decrease in P50 amplitude of the S1 stimulus and reversal by rivastigmine. Moreover, they are in contrast with the study of Buchanan et al. (2002) reporting modest effects of donepezil on P50 gating (but see Cancelli et al. 2006). Furthermore, Buchwald et al. (1991) reported a disappearance of the P50 by the muscarinic antagonist scopolamine and reversal by concomitant administration of a cholinesterase inhibitor. However, please note that in the experiment by Buchwald et al. (1991) trains of clicks with an ISI of 1 s were presented, whereas in the current study, we used paired clicks spaced $500 \mathrm{~ms}$ apart. The discrepancy in the findings of Buchwald et al. (1991) compared to our own might also be explained by differences in binding affinity between scopolamine and biperiden, i.e., scopolamine blocks muscarinic receptors nonselectively, whereas biperiden is relatively more selective for the muscarinic M1 receptor. A general increase in P50 amplitude after biperiden might reflect a compensatory preattentional mechanism for a general arousal-deteriorating effect of biperiden (Thomas et al. 2010).

Relating our findings to the P50 suppression deficits reported in schizophrenia is not very straightforward. In contrast to the effects of biperiden, impaired P50 suppression (i.e., inflated $\mathrm{S} 2 / \mathrm{S} 1$ ratio) in schizophrenia has generally been attributed to a reduction of the initial P50 response to S1 (Clementz and Blumenfeld 2001; Jin et al. 1998; Jin et al. 1997; Johannesen et al. 2005; but see Hong et al. 2009; Williams et al. 2011). Some authors have argued that this decrement might be due to higher P50 latency variability (Jin et al. 1997; Patterson et al. 2000). However, this cannot explain our results of larger P50 amplitude after biperiden, as high temporal variability in P50 latency would cause a reduction in P50 amplitude. Arguably, effects of schizophrenia status and (anti-)cholinergic drugs on the P50 as reported in the literature are likely mediated by a muscarinic receptor subtype other than M1 (i.e., M2-M5) or, alternatively, by nicotinic receptors (Adler et al. 1998).

Of note, there have been reports of enhanced P50 amplitude in aging, mild cognitive impairment, and Alzheimer's disease using a variety of auditory paradigms (Cancelli et al. 2006; Golob et al. 2007; Golob et al. 2001a; Golob et al. 2001b; Irimajiri et al. 2005; Thomas et al. 2010; but see Ally 


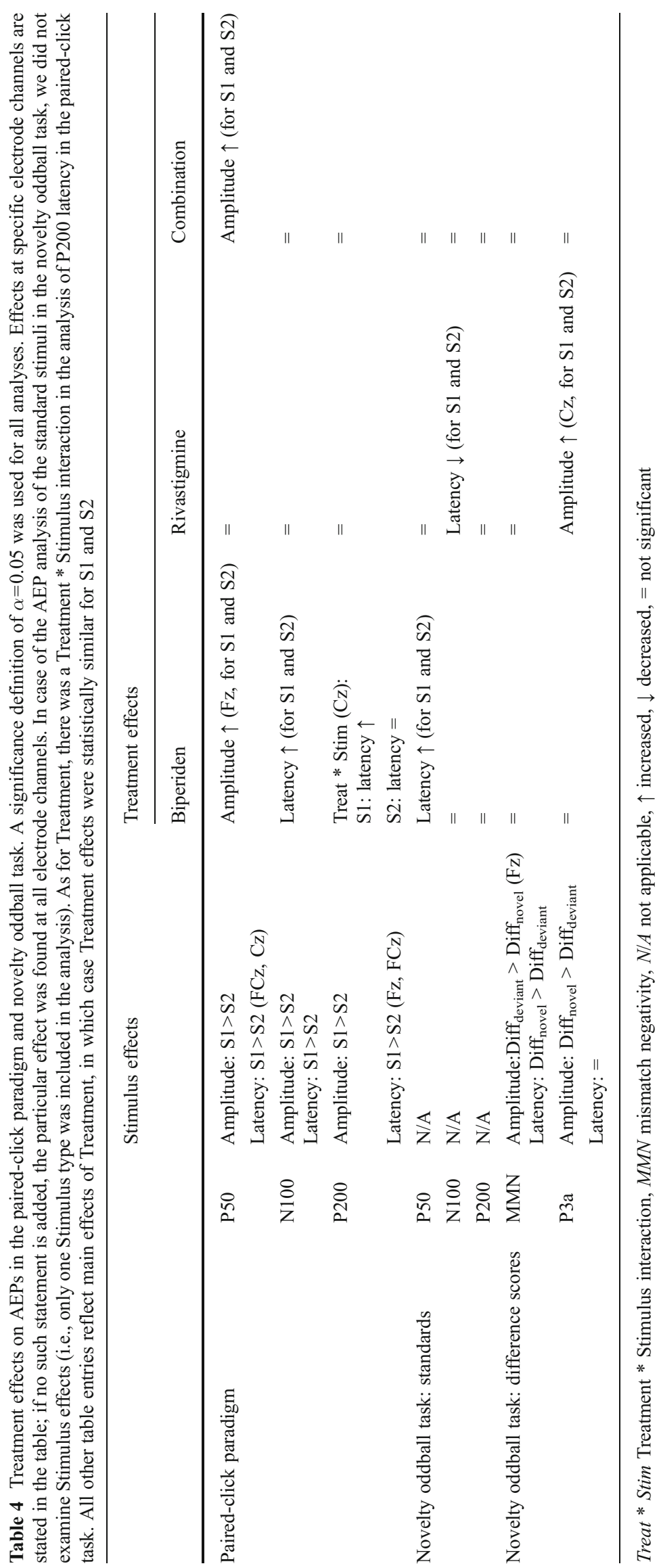


et al. 2006; Fein et al. 1994; Gmehlin et al. 2011). Possibly, the increment in P50 amplitude seen in healthy aging and agerelated neurodegenerative disorders might mirror those seen after biperiden and hence, might be muscarinic M1-mediated.

Early attentive processing: biperiden delayed N100 latency, which was reversed by rivastigmine

An additional effect we found in the paired-click task was a delay in N100 latency after biperiden, which was reversed by concurrent treatment with rivastigmine (see Fig. 3). This reflects a general arousal effect of biperiden on early attentional processing. Rivastigmine itself did not affect N100 latency in the paired-click task. These findings would suggest that the effect of biperiden on N100 latency might be M1mediated. Furthermore, it is likely that changes in neurotransmission at M2-M5 or nicotinic receptors are capable of interacting with the effects of biperiden at the M1 receptor given the fact that rivastigmine was able to reverse the biperideninduced delay in N100 latency. Effects of muscarinic antagonists on the auditory N100 component in paired-click paradigms have not been assessed previously. There are some studies which have used oddball paradigms and reported scopolamine-induced delays in N100 latency (Pekkonen et al. 2001; Pekkonen et al. 2005). Of note, although basic AEPs (i.e., P50-N100-P200 complex) can be assessed by pairedclick and novelty oddball paradigms, these tasks are not fully comparable, that is, paired-click tasks assess gating-out, whereas novelty measure gating-in processes.

Paired-click studies in schizophrenia generally report disruptions of N100 gating and reductions in N100 amplitude (Boutros et al. 2009; Boutros et al. 2004; Brockhaus-Dumke et al. 2008; Clementz and Blumenfeld 2001; Gjini et al. 2010; Kisley et al. 2003) but no changes in N100 latency (e.g., Clementz and Blumenfeld 2001). Moreover, in paired-click paradigms, aged participants are also generally found to have N100 latencies comparable to those of healthy controls (Clementz and Blumenfeld 2001; Gmehlin et al. 2011; Kisley et al. 2005). Of note, using oddball tasks delays in N100 latency have been reported in schizophrenic patients (Simons et al. 2011), aged participants (Iragui et al. 1993; but see Amenedo and Diaz 1998), and people with age-associated memory impairment (Anderer et al. 2003). However, novelty oddball and paired-click paradigms are not fully comparable.

Late attentive processing: biperiden delayed P200 latency of $S 1$, which was reversed by rivastigmine

In the paired-click task, biperiden induced a delay in P200 latency of the S1, but not S2 stimulus, which was reversed by concurrent administration of rivastigmine. This reflects a general arousal effect of biperiden on late attentional processing. Rivastigmine by itself did not affect P200 latency in the paired-click task. However, as Simons et al. (2011) indicated, slowing of initial auditory processing might have downstream consequences for later peaks, i.e., delayed latency of the N100 component might also retard the occurrence of the P200. As of yet, no studies have looked into P200 latency deficits in schizophrenia using paired-click paradigms. However, a delay in P200 latency has been reported in aged participants (Anderer et al. 1996; Ford and Pfefferbaum 1991; Gmehlin et al. 2011; Iragui et al. 1993; but see Anderer et al. 2003), but not in MCI (Anderer et al. 2003; Golob et al. 2007; Golob et al. 2001b) or Alzheimer patients (Boutros et al. 1995; Golob et al. 2007).

Novelty oddball task

Preattentive processing: P50 latency was delayed after biperiden, which was reversed by rivastigmine

Biperiden induced a slowing of preattentive auditory processing, reflected by a delay in P50 latency which was reversed by concurrent treatment with rivastigmine. This reflects a general arousal effect of biperiden on preattentional processing and was in line with our hypothesis. Rivastigmine by itself did not affect P50 latency in the novelty oddball task. These findings would suggest that the effect of biperiden on P50 latency is M1-mediated. Furthermore, it is likely that changes in neurotransmission at M2-M5 receptors can interact with the effects of biperiden at the M1 receptor given the fact that rivastigmine was able to reverse the biperideninduced delay in P50 latency. Pekkonen et al. (2005) also found a delay in the occurrence of the P50 after administration of scopolamine (but see Curran et al. 1998).

As P50 latency has not been assessed in schizophrenia patients presented with a novelty oddball paradigm, it is unclear whether this component is affected. However, in paired-click tasks, P50 latency of schizophrenia patients is generally unchanged relative to normal controls (e.g., Bramon et al. 2004b). Interestingly, P50 latency has also been shown to be delayed in mild cognitive impairment (Golob et al. 2001b; but see Golob et al. 2007) but is unaffected in aging (Golob et al. 2007) and Alzheimer's disease (Boutros et al. 1995; Golob et al. 2007). However, these studies have used active oddball paradigms requiring a behavioral response, whereas our paradigm was fully passive.

\section{Early attentive processing: rivastigmine shortened N100} latency which was reversed by biperiden

After rivastigmine, the N100 peak to standard stimuli occurred earlier compared to the placebo condition (see Fig. 5). This finding reflects an enhancement of early attentional processing by rivastigmine. Studies on cholinesterase 
inhibitors have generally reported effects on components other than the N100, such as the P300 component (e.g., Meador et al. 1987; Meador et al. 1988; Onofrj et al. 2003). Concurrent treatment with biperiden reversed the rivastigmine-induced effects, whereas biperiden by itself did not affect N100 latency in the novelty oddball paradigm. The latter finding is in line with a lack of effect of scopolamine on N100 latency in oddball paradigms (Curran et al. 1998; Meador et al. 1987; Meador et al. 1995; Meador et al. 1988; Potter et al. 2000; but see Pekkonen et al. 2005). The fact that biperiden failed to influence N100 latency suggests an effect of rivastigmine which is mediated by a cholinergic receptor different than the M1, i.e., M2-M5 or nicotinic receptors. Rivastigmine enhances cholinergic signaling nonselectively, which means that nicotinergic and/or muscarinic receptors other than $\mathrm{M} 1$ might also instigate changes in the N100 component (Kadir et al. 2007; but see Inami et al. 2005). However, it is likely that M1-mediated neurotransmission can interact with the effects of rivastigmine given the fact that biperiden was able to reverse the rivastigmineinduced decrease in N100 latency.

Findings of delayed N100 latency in schizophrenia patients and their siblings (e.g., Simons et al. 2011; but see Karoumi et al. 2000; Laurent et al. 1999; van der Stelt et al. 2005), aged participants (Anderer et al. 1996; Golob et al. 2007; Iragui et al. 1993; but see Amenedo and Diaz 1998), and people with age-associated memory impairment (Anderer et al. 2003) suggest that rivastigmine might be beneficial for alleviating deficits in attentional processing. This is in accordance with studies reporting beneficial effects of cholinesterase inhibitors on tests of attention and memory (Friedman 2004; Schubert et al. 2006; but see Dyer et al. 2008; Friedman et al. 2002; Lee et al. 2007).

\section{Change detection: no effects of biperiden, rivastigmine, and the combination treatment on MMN parameters}

Unexpectedly, we did not find an effect of biperiden or rivastigmine on the MMN, which suggests that muscarinic M1 receptors are not involved in the frontal MMN component. This finding was unexpected given our assumption that rivastigmine would increase MMN amplitude. Pharmacological studies on cholinergic signaling and MMN have reported conflicting data. For instance, using a passive novelty oddball task, Pekkonen et al. (2005) also showed no effect of scopolamine on MMN. However, a MEG study by Pekkonen et al. (2001) reported a reduction of MMNm amplitude by the nonselective muscarinic antagonist scopolamine. However, this discrepancy might be partly explained by differences in sensitivity between MEG and EEG (Hämäläinen et al. 1993). Specifically, the MMN seen in MEG originates in the auditory cortex and occurs relatively earlier than the EEG-based MMN, which is mainly generated by the frontal cortex (Rinne et al. 2000). In schizophrenia (e.g., Baldeweg et al. 2004; Bramon et al. 2004a; Light and Braff 2005; Price et al. 2006; Turetsky et al. 2009) and aging (Pekkonen et al. 1993; Schiff et al. 2008), but not in Alzheimer's disease (Pekkonen et al. 1994; Riekkinen et al. 1997), MMN amplitude is found to be decreased.

Novelty processing: rivastigmine enhanced P3a amplitude, which was reversed by biperiden

In the novelty oddball task, rivastigmine increased novelty processing, reflected by an enhancement of P3a amplitude of the difference wave at the $\mathrm{Cz}$ electrode (see Fig. 7). Thisis indicative of an enhancement of novelty processing by rivastigmine. Concurrent treatment with biperiden reversed the rivastigmine-induced effects, whereas biperiden by itself did not affect P3a amplitude in the novelty oddball paradigm. The latter finding was unanticipated given our hypothesis stating that biperiden would decrease P3a amplitude. The fact that biperiden failed to influence the P3a suggests an effect of rivastigmine which is mediated by a cholinergic receptor different than the M1, i.e., M2-M5 or nicotinic receptors. However, it is likely that M1-mediated neurotransmission can interact with the effects of rivastigmine given the fact that biperiden was able to reverse the rivastigmine-induced increase in P3a amplitude.

Since this is the first study reporting effects of cholinergic drugs on P3a amplitude using a passive novelty oddball task, it is difficult to relate our findings to those found in the literature. There exist a few studies on the effects of scopolamine which have reported a smaller P300 amplitude (Curran et al. 1998; Meador et al. 1987; Meador et al. 1989; Meador et al. 1995; but see Meador et al. 1988) and subsequent reversal by the cholinesterase inhibitor physostigmine (Meador et al. 1987). However, all of these studies used an active oddball paradigm, in which participants are instructed to give a behavioral response to target stimuli. Due to the higher attentional effort which must be paid, active oddball paradigms generally induce a parietal $\mathrm{P} 3 \mathrm{~b}$ reflecting context updating/working memory function, instead of a frontocentral P3a peak indicative of novelty/attentional processes (Comerchero and Polich 1999; Donchin 1981).

In schizophrenia, decreased P3a amplitude has been reported, which is generally interpreted as a reduction in attentional capacity or, alternatively, as a change in allocation of processing resources (Grillon et al. 1990; Turetsky et al. 2000). Again, the clinical specificity for P3a abnormalities is low; the P3a is also smaller and delayed in aged subjects (Fjell and Walhovd 2004; Fjell et al. 2007; Knight 1987; Pontifex et al. 2009). Findings of P3a abnormalities in schizophrenia and aging could be indicative of a 
common underlying frontal impairment sensitive to treatment by cholinesterase inhibitors.

Paired-click versus novelty oddball task

We found several dissociations in terms of treatment effects between the two auditory paradigms used in the current study. Overall, it appears that the paired-click paradigm was relatively more sensitive to changes in muscarinic neurotransmission, especially those induced by biperiden. It is difficult to account for the discrepancies in treatment effects between the tasks. Paired-click paradigms present participants with a repetitive sequence consisting of uniform sounds and thus assess the sensory filtering of incoming stimuli which are deemed uninformative (e.g., Kisley et al. 2004). Novelty oddball tasks provide participants with stimuli which differ in terms of frequency of occurrence (i.e., deviants and novels) embedded in a string of familiar sounds (i.e., standards) and hence measure auditory deviation from familiarity (e.g., Kisley et al. 2004). Although we chose to analyze treatment effects on the P50, N100, and P200 AEPs of just the standard stimuli in the novelty oddball task, the presence of infrequently occurring deviant or novel sounds might already change the auditory processing of the standards compared to a task which uses uniform stimuli (as was the case for the paired-click task). For instance, the presence of infrequent sounds in the novelty oddball task might have reduced the impact of sensory filtering mechanisms on the frequent stimuli simply because participants show less habituation to these sounds. In short, although both paired-click paradigms and novelty oddball tasks employ auditory stimuli, they assess distinct sensory processes. Biperiden and rivastigmine have differential effects on the AEPs generated by these paradigms.

\section{Questionnaires}

With regards to the questionnaires, participants were found to be less energetic on the POMS after biperiden and rivastigmine (see Table 3). However, the POMS questionnaire also indicated that biperiden and rivastigmine made the volunteers feel less tired and that biperiden made them even feel happier. This latter finding is in line with previous studies reporting an antidepressant effect of scopolamine (Furey and Drevets 2006; Furey et al. 2010). In contrast, the Bond and Lader subscale we used, alert-drowsy, did not yield any treatment effects. Furthermore, our self-report questionnaire also included some questions pertaining to energy level of the participants (i.e., sleepiness, tiredness, drowsiness, and listlessness). However, no changes in selfreport complaints were noted after our treatment conditions. On the basis of the questionnaire data, it is, therefore, unclear whether the participants experienced any significant sedative side effects. However, four participants dropped out of the study prematurely, so this cannot be excluded.

\section{Conclusions}

Biperiden increased P50 amplitude but did not affect sensory gating in the paired-click task. Biperiden also prolonged N100 and P200 latency; however, we presume that the delayed latency of later-occurring peaks (i.e., P200) is likely due to slowing of initial auditory processing after biperiden (i.e., N100). Rivastigmine was able to reverse the biperiden-induced delay in $\mathrm{N} 100$ and P200 latency in the paired-click task but was unable to do so for the increment in P50 amplitude after biperiden. As for the novelty oddball task, biperiden increased P50 latency which was reversed by concurrent administration of rivastigmine. Rivastigmine shortened N100 latency and enhanced P3a amplitude, both of which were reversed by biperiden.

Overall, attributing specific treatment effects on AEPs to the muscarinic M1 receptor is not very straightforward. The only exception is the effect of biperiden on preattentive processing (i.e., P50 amplitude) in the paired-click task, which was truly independent from that of rivastigmine. There also seems to be a role for the M1 receptor in early attentive mechanisms (i.e., N100 latency) in the paired-click task, and in preattentive processing (i.e., P50 latency) in the novelty oddball paradigm. However, reversal of effects of biperiden by concurrent rivastigmine treatment makes the evidence in favor of M1 mediation much more equivocal. Muscarinic receptors other than M1 (i.e., M2-M5) and nicotinic receptors appear to be important for early attentive (N100 latency) and novelty processing (i.e., P3a amplitude) in the novelty oddball paradigm. Yet again, reversal of effects of rivastigmine by concurrent biperiden treatment is not fully reflective of a role for M2-M5 and/or nicotinic, but not M1 receptors.

It remains to be seen whether the effects of cholinergic drugs on AEPs are specifically related to the abnormalities found in schizophrenia. Indeed, the usefulness of some of these markers as endophenotypes for schizophrenia has been questioned (e.g., Simons et al. 2011). Alternatively, aberrant auditory processing could also be indicative of a general disturbance in neural functioning shared by several neuropsychiatric disorders and/or neurodegenerative changes seen in aging. Future experimental research should focus on determining whether there exists some degree of dissociation between muscarinic receptor subtypes in terms of their involvement in normal and pathological auditory processing. This would be beneficial for discovering specific trait markers of different neuropsychiatric disorders. Furthermore, new studies investigating the role of 
muscarinic receptors in auditory processing should look into dissociations between effects of muscarinic M1 antagonists and cholinesterase inhibitors on sensory gating (i.e., gating out) versus novelty processing (i.e., gating in). This can be done by experimentally varying the task parameters of paired-click and/or novelty oddball paradigms (e.g., stimulus intensity, duration, and/or pitch, interstimulus or interpair interval, and stimulus frequency) to determine which aspects of these tasks are most sensitive to changes in muscarinic signaling.

Acknowledgments We would like to thank Suzanne Holthuijsen, Karin Joanknecht, and Conny Quaedflieg for their assistance with the EEG recording.

Conflict of interest The authors declare that, except for income received from their primary employer, no financial support or compensation has been received from any individual or corporate entity over the past three years for research or professional service. There are no personal financial holdings that could be perceived as constituting a potential conflict of interest. The authors have full control of all primary data and agree to allow the journal to review data if requested.

\section{References}

Adler LE, Pachtman E, Franks RD, Pecevich M, Waldo MC, Freedman R (1982) Neurophysiological evidence for a defect in neuronal mechanisms involved in sensory gating in schizophrenia. Biol Psychiatry 17:639-654

Adler LE, Olincy A, Waldo M, Harris JG, Griffith J, Stevens K, Flach K, Nagamoto H, Bickford P, Leonard S, Freedman R (1998) Schizophrenia, sensory gating, and nicotinic receptors. Schizophrenia Bull 24:189-202

Ally BA, Jones GE, Cole JA, Budson AE (2006) Sensory gating in patients with Alzheimer's disease and their biological children. Am J Alzheimers Dis Other Demen 21:439-447

Amenedo E, Diaz F (1998) Aging-related changes in processing of non-target and target stimuli during an auditory oddball task. Biol Psychol 48:235-267

Anderer P, Semlitsch HV, Saletu B (1996) Multichannel auditory event-related brain potentials: effects of normal aging on the scalp distribution of N1, P2, N2 and P300 latencies and amplitudes. Electroencephalogr Clin Neurophysiol 99:458-472

Anderer P, Saletu B, Semlitsch HV, Pascual-Marqui RD (2003) Noninvasive localization of P300 sources in normal aging and ageassociated memory impairment. Neurobiol Aging 24:463-479

Baldeweg T, Klugman A, Gruzelier J, Hirsch SR (2004) Mismatch negativity potentials and cognitive impairment in schizophrenia. Schizophr Res 69:203-217

Bolden C, Cusack B, Richelson E (1992) Antagonism by antimuscarinic and neuroleptic compounds at the five cloned human muscarinic cholinergic receptors expressed in Chinese hamster ovary cells. J Pharmacol Exp Ther 260:576-580

Bond A, Lader M (1974) The use of analogue scales in rating subjective feelings. Brit J Med Psychol 80:1-46

Bora E, Veznedaroglu B, Kayahan B (2005) The effect of galantamine added to clozapine on cognition of five patients with schizophrenia. Clin Neuropharmacol 28:139-141
Boutros N, Torello MW, Burns EM, Wu SS, Nasrallah HA (1995) Evoked potentials in subjects at risk for Alzheimer's disease. Psychiatry Res 57:57-63

Boutros NN, Korzyukov O, Jansen B, Feingold A, Bell M (2004) Sensory gating deficits during the mid-latency phase of information processing in medicated schizophrenia patients. Psychiatry Res 126:203-215

Boutros NN, Brockhaus-Dumke A, Gjini K, Vedeniapin A, Elfakhani M, Burroughs S, Keshavan M (2009) Sensory-gating deficit of the N100 mid-latency auditory evoked potential in medicated schizophrenia patients. Schizophr Res 113:339-346

Bramon E, Croft RJ, McDonald C, Virdi GK, Gruzelier JG, Baldeweg T, Sham PC, Frangou S, Murray RM (2004a) Mismatch negativity in schizophrenia: a family study. Schizophr Res 67:1-10

Bramon E, Rabe-Hesketh S, Sham P, Murray RM, Frangou S (2004b) Meta-analysis of the P300 and P50 waveforms in schizophrenia. Schizophr Res 70:315-329

Brockhaus-Dumke A, Schultze-Lutter F, Mueller R, Tendolkar I, Bechdolf A, Pukrop R, Klosterkoetter J, Ruhrmann S (2008) Sensory gating in schizophrenia: P50 and N100 gating in antipsychotic-free subjects at risk, first-episode, and chronic patients. Biol Psychiatry 64:376-384

Buchanan RW, Summerfelt A, Tek C, Gold J (2002) An open-label trial of adjunctive donepezil for cognitive impairments in patients with schizophrenia. Schizophr Res 59:29-33

Buchanan RW, Conley RR, Dickinson D, Ball MP, Feldman S, Gold JM, McMahon RP (2008) Galantamine for the treatment of cognitive impairments in people with schizophrenia. Am J Psychiatry 165:82-89

Buchwald JS, Rubinstein EH, Schwafel J, Strandburg RJ (1991) Midlatency auditory evoked responses: differential effects of a cholinergic agonist and antagonist. Electroencephalogr Clin Neurophysiol 80:303-309

Cancelli I, Cadore IP, Merlino G, Valentinis L, Moratti U, Bergonzi P, Gigli GL, Valente M (2006) Sensory gating deficit assessed by $\mathrm{P} 50 / \mathrm{Pb}$ middle latency event related potential in Alzheimer's disease. J Clin Neurophysiol 23:421-425

Clementz BA, Blumenfeld LD (2001) Multichannel electroencephalographic assessment of auditory evoked response suppression in schizophrenia. Exp Brain Res 139:377-390

Comerchero MD, Polich J (1999) P3a and P3b from typical auditory and visual stimuli. Clin Neurophysiol 110:24-30

Curran HV, Pooviboonsuk P, Dalton JA, Lader MH (1998) Differentiating the effects of centrally acting drugs on arousal and memory: an event-related potential study of scopolamine, lorazepam and diphenhydramine. Psychopharmacology 135:27-36

Donchin E (1981) Surprise!...Surprise? Psychophysiology 18:493513

Dyer MA, Freudenreich O, Culhane MA, Pachas GN, Deckersbach T, Murphy E, Goff DC, Evins AE (2008) High-dose galantamine augmentation inferior to placebo on attention, inhibitory control and working memory performance in nonsmokers with schizophrenia. Schizophr Res 102:88-95

Erwin RJ, Turetsky BI, Moberg P, Gur RC, Gur RE (1998) P50 abnormalities in schizophrenia: relationship to clinical and neuropsychological indices of attention. Schizophr Res 33:157-167

Farlow MR (2003) Update on rivastigmine. Neurologist 9:230-234

Fein G, Biggins C, Van Dyke C (1994) The auditory P50 response is normal in Alzheimer's disease when measured via a paired click paradigm. Electroencephalogr Clin Neurophysiol 92:536-545

Fjell AM, Walhovd KB (2004) Life-span changes in P3a. Psychophysiology 41:575-583

Fjell AM, Walhovd KB, Fischl B, Reinvang I (2007) Cognitive function, $\mathrm{P} 3 \mathrm{a} / \mathrm{P} 3 \mathrm{~b}$ brain potentials, and cortical thickness in aging. Hum Brain Mapp 28:1098-1116 
Ford JM (1999) Schizophrenia: the broken P300 and beyond. Psychophysiology 36:667-682

Ford JM, Pfefferbaum A (1991) Event-related potentials and eyeblink responses in automatic and controlled processing: effects of age. Electroencephalogr Clin Neurophysiol 78:361-377

Friedman JI (2004) Cholinergic targets for cognitive enhancement in schizophrenia: focus on cholinesterase inhibitors and muscarinic agonists. Psychopharmacology 174:45-53

Friedman JI, Adler DN, Howanitz E, Harvey PD, Brenner G, Temporini H, White L, Parrella M, Davis KL (2002) A double blind placebo controlled trial of donepezil adjunctive treatment to risperidone for the cognitive impairment of schizophrenia. Biol Psychiatry 51:349 357

Furey ML, Drevets WC (2006) Antidepressant efficacy of the antimuscarinic drug scopolamine: a randomized, placebo-controlled clinical trial. Arch Gen Psychiatry 63:1121-1129

Furey ML, Khanna A, Hoffman EM, Drevets WC (2010) Scopolamine produces larger antidepressant and antianxiety effects in women than in men. Neuropsychopharmacol 35:2479-2488

Garrido MI, Kilner JM, Stephan KE, Friston KJ (2009) The mismatch negativity: a review of underlying mechanisms. Clin Neurophysiol 120:453-463

Gjini K, Arfken C, Boutros NN (2010) Relationships between sensory "gating out" and sensory "gating in" of auditory evoked potentials in schizophrenia: a pilot study. Schizophr Res 121:139-145

Gmehlin D, Kreisel SH, Bachmann S, Weisbrod M, Thomas C (2011) Age effects on preattentive and early attentive auditory processing of redundant stimuli: is sensory gating affected by physiological aging? J Gerontol A Biol Sci Med Sci 66:1043-1053

Golob EJ, Johnson JK, Starr A (2001a) Auditory event-related potentials during target detection are abnormal in mild cognitive impairment. Clin Neurophysiol 113:151-161

Golob EJ, Miranda GG, Johnson JK, Starr A (2001b) Sensory cortical interactions in aging, mild cognitive impairment, and Alzheimer's disease. Neurobiol Aging 22:755-763

Golob EJ, Irimajiri R, Starr A (2007) Auditory cortical activity in amnestic mild cognitive impairment: relationship to subtype and conversion to dementia. Brain 130:740-752

Grillon C, Courchesne E, Ameli R, Geyer MA, Braff DL (1990) Increased distractibility in schizophrenic patients. Electrophysiologic and behavioral evidence. Arch Gen Psychiatry 47:171-179

Grunwald T, Boutros NN, Pezer N, von Oertzen J, Fernandez G, Schaller C, Elger CE (2003) Neuronal substrates of sensory gating within the human brain. Biol Psychiatry 53:511-519

Hall MH, Schulze K, Bramon E, Murray RM, Sham P, Rijsdijk F (2006) Genetic overlap between P300, P50, and duration mismatch negativity. Am J Med Genet B Neuropsychiatr Genet 141B:336-343

Hämäläinen M, Hari R, Ilmoniemi RJ, Knuutila J, Lounasmaa OV (1993) Magnetoencephalography - theory, instrumentation, and applications to noninvasive studies of the working human brain. Rev Mod Phys 65:413-497

Hollmann M, Brode E, Greger G, Müller-Peltzer H, Wetzelsberger N (1984) Biperiden effects and plasma levels in volunteers. Eur J Clin Pharmacol 27:619-621

Hollmann M, Müller-Peltzer H, Greger G, Brode E, Perucca E, Grimaldi R, Crema A (1987) Pharmacokinetic-dynamic study on different oral biperiden formulations in volunteers. Pharmacopsychiatry 20:72-77

Hong X, Chan RC, Zhuang X, Jiang T, Wan X, Wang J, Xiao B, Zhou H, Jiang L, Weng B (2009) Neuroleptic effects on P50 sensory gating in patients with first-episode never-medicated schizophrenia. Schizophr Res 108:151-157

Inami R, Kirino E, Inoue R, Arai H (2005) Transdermal nicotine administration enhances automatic auditory processing reflected by mismatch negativity. Pharmacol Biochem Behav 80:453-461
Iragui VJ, Kutas M, Mitchiner MR, Hillyard SA (1993) Effects of aging on event-related brain potentials and reaction times in an auditory oddball task. Psychophysiology 30:10-22

Irimajiri R, Golob EJ, Starr A (2005) Auditory brain-stem, middle- and long-latency evoked potentials in mild cognitive impairment. Clin Neurophysiol 116:1918-1929

Jann MW, Shirley KL, Small GW (2002) Clinical pharmacokinetics and pharmacodynamics of cholinesterase inhibitors. Clin Pharmacokinet 41:719-739

Jasper H (1958) The ten-twenty electrode system of the international federation. Electroencephalogr Clin Neurophysiol 10:371-375

Javitt DC, Spencer KM, Thaker GK, Winterer G, Hajós M (2008) Neurophysiological biomarkers for drug development in schizophrenia. Nat Rev Drug Discov 7:68-83

Jeon YW, Polich J (2001) P300 asymmetry in schizophrenia: a metaanalysis. Psychiatry Res 104:61-74

Jin Y, Potkin SG, Patterson JV, Sandman CA, Hetrick WP, Bunney WE Jr (1997) Effects of P50 temporal variability on sensory gating in schizophrenia. Psychiatry Res 70:71-81

Jin Y, Bunney WE Jr, Sandman CA, Patterson JV, Fleming K, Moenter JR, Kalali AH, Hetrick WP, Potkin SG (1998) Is P50 suppression a measure of sensory gating in schizophrenia? Biol Psychiatry 43:873-878

Johannesen JK, Kieffaber PD, O'Donnell BF, Shekhar A, Evans JD, Hetrick WP (2005) Contributions of subtype and spectral frequency analyses to the study of P50 ERP amplitude and suppression in schizophrenia. Schizophr Res 78:269-284

Johnstone EC, Crow TJ, Ferrier IN, Frith CD, Owens DGC, Bourne RC, Gamble SJ (1983) Adverse effects of anticholinergic medication on positive schizophrenic symptoms. Psychol Med 13:513-527

Juckel G, Clotz F, Frodl T, Kawohl W, Hampel H, Pogarell O, Hegerl U (2008) Diagnostic usefulness of cognitive auditory eventrelated p300 subcomponents in patients with Alzheimers disease? J Clin Neurophysiol 25:147-152

Kadir A, Darreh-Shori T, Almkvist O, Wall A, Langstrom B, Nordberg A (2007) Changes in brain 11C-nicotine binding sites in patients with mild Alzheimer's disease following rivastigmine treatment as assessed by PET. Psychopharmacology 191:1005-1014

Karoumi B, Laurent A, Rosenfeld F, Rochet T, Brunon AM, Dalery J, d'Amato T, Saoud M (2000) Alteration of event related potentials in siblings discordant for schizophrenia. Schizophr Res 41:325334

Katayama S, Ishizaki F, Yamamura Y, Khoriyama T, Kito S (1990) Effects of anticholinergic antiparkinsonian drugs on binding of muscarinic receptor subtypes in rat brain. Res Commun Chem Path 69:261-270

Kisley MA, Olincy A, Robbins E, Polk SD, Adler LE, Waldo MC, Freedman R (2003) Sensory gating impairment associated with schizophrenia persists into REM sleep. Psychophysiology 40:29 38

Kisley MA, Noecker TL, Guinther PM (2004) Comparison of sensory gating to mismatch negativity and self-reported perceptual phenomena in healthy adults. Psychophysiology 41:604 612

Kisley MA, Davalos DB, Engleman LL, Guinther PM, Davis HP (2005) Age-related change in neural processing of timedependent stimulus features. Cogn Brain Res 25:913-925

Knight RT (1987) Aging decreases auditory event-related potentials to unexpected stimuli in humans. Neurobiol Aging 8:109-113

Laurent A, Garcia-Larrea L, d'Amato T, Bosson JL, Saoud M, MarieCardine M, Maugiere F, Dalery J (1999) Auditory event-related potentials and clinical scores in unmedicated schizophrenic patients. Psychiatry Res 86:229-238

Lee BJ, Lee JG, Kim YH (2007) A 12-week, double-blind, placebocontrolled trial of donepezil as an adjunct to haloperidol for 
treating cognitive impairments in patients with chronic schizophrenia. J Psychopharmacol 21:421-427

Lefevre G, Sedek G, Jhee SS, Leibowitz MT, Huang HL, Enz A, Maton S, Ereshefsky L, Pommier F, Schmidli H, AppelDingemanse S (2008) Pharmacokinetics and pharmacodynamics of the novel daily rivastigmine transdermal patch compared with twice-daily capsules in Alzheimer's disease patients. Clin Pharmacol Ther 83:106-114

Leiser SC, Dunlop J, Bowlby MR, Devilbiss DM (2011) Aligning strategies for using EEG as a surrogate biomarker: a review of preclinical and clinical research. Biochem Pharmacol 81:1408-1421

Light GA, Braff DL (2005) Mismatch negativity deficits are associated with poor functioning in schizophrenia patients. Arch Gen Psychiatry $62: 127-136$

Lijffijt M, Lane SD, Meier SL, Boutros NN, Burroughs S, Steinberg JL, Moeller FG, Swann AC (2009) P50, N100 and P200 sensory gating: relationships with behavioral inhibition, attention, and working memory. Psychophysiology 46:1059-1068

McGhie A, Chapman J (1961) Disorders of attention and perception in early schizophrenia. Br J Med Psychol 34:103-116

McNair DM, Lorr M, Droppleman LF (1971) Manual for the profile of mood states. Educational and Industrial Testing Service, Educational and Industrial Testing Service

Meador KJ, Loring DW, Adams RJ, Patel BR, Davis HC, Hammond EJ (1987) Central cholinergic systems and the P3 evoked potential. Int J Neurosci 33:199-205

Meador KJ, Loring DW, Lee GP, Taylor HS, Hughes DR, Feldman DS (1988) In vivo probe of central cholinergic systems. J Gerontol 43:M158-M162

Meador KJ, Loring DW, Davis HC, Sethi KD, Patel BR, Adams RJ, Hammond EJ (1989) Cholinergic and serotonergic effects on the P3 potential and recent memory. J Clin Exp Neuropsychol $11: 252-260$

Meador KJ, Loring DW, Hendrix N, Nichols ME, Oberzan R, Moore EE (1995) Synergistic anticholinergic and antiserotonergic effects in humans. J Clin Exp Neuropsychol 17:611-621

Mintzer J, Burns A (2000) Anticholinergic side-effects of drugs in elderly people. J R Soc Med 93:457-462

Miranda MI, Ramirez-Lugo L, Bermudez-Rattoni F (2000) Cortical cholinergic activity is related to the novelty of the stimulus. Brain Res 882:230-235

Näätänen R, Pakarinen S, Rinne T, Takegata R (2004) The mismatch negativity (MMN): towards the optimal paradigm. Clin Neurophysiol 115:140-144

Nagamoto HT, Adler LE, Waldo MC, Freedman R (1989) Sensory gating in schizophrenics and normal controls: effects of changing stimulation interval. Biol Psychiatry 25:549-561

Ogino S, Miyamoto S, Tenjin T, Kitajima R, Ojima K, Miyake N, Funamoto Y, Arai J, Tsukahara S, Ito Y, Tadokoro M, Anai K, Tatsunami S, Kubota H, Kaneda Y, Yamaguchi S (2011) Effects of discontinuation of long-term biperiden use on cognitive function and quality of life in schizophrenia. Prog Neuro-Psychopharmacol Biol Psychiatry 35:78-83

Olincy A, Braff DL, Adler LE, Cadenhead KS, Calkins ME, Dobie DJ, Green MF, Greenwood TA, Gur RE, Gur RC, Light GA, Mintz J, Nuechterlein KH, Radant AD, Schork NJ, Seidman LJ, Siever LJ, Silverman JM, Stone WS, Swerdlow NR, Tsuang DW, Tsuang MT, Turetsky BI, Wagner BD, Freedman R (2010) Inhibition of the P50 cerebral evoked response to repeated auditory stimuli: results from the Consortium on Genetics of Schizophrenia. Schizophr Res 119:175-182

Onofrj M, Thomas A, Iacono D, Luciano AL, Di Iorio A (2003) The effects of a cholinesterase inhibitor are prominent in patients with fluctuating cognition: a part 3 study of the main mechanism of cholinesterase inhibitors in dementia. Clin Neuropharmacol 26:239-251
Oranje B, Geyer MA, Bocker KBE, Kenemans JL, Verbaten MN (2006) Prepulse inhibition and P50 suppression: commonalities and dissociations. Psychiatry Res 143:147-158

Patterson JV, Jin Y, Gierczak M, Hetrick WP, Potkin S, Bunney WE Jr, Sandman CA (2000) Effects of temporal variability on P50 and the gating ratio in schizophrenia: a frequency domain adaptive filter single-trial analysis. Arch Gen Psychiatry 57:57-64

Pekkonen E, Jousmaki V, Partanen J, Karhu J (1993) Mismatch negativity area and age-related auditory memory. Electroencephalogr Clin Neurophysiol 87:321-325

Pekkonen E, Jousmaki V, Kononen M, Reinikainen K, Partanen J (1994) Auditory sensory memory impairment in Alzheimer's disease: an event-related potential study. NeuroReport 5:25372540

Pekkonen E, Hirvonen J, Jaaskelainen IP, Kaakkola S, Huttunen J (2001) Auditory sensory memory and the cholinergic system: implications for Alzheimer's disease. Neurolmage 14:376-382

Pekkonen E, Jaaskelainen IP, Kaakkola S, Ahveninen J (2005) Cholinergic modulation of preattentive auditory processing in aging. NeuroImage 27:387-392

Pontifex MB, Hillman CH, Polich J (2009) Age, physical fitness, and attention: P3a and P3b. Psychophysiology 46:379-387

Potter DD, Pickles CD, Roberts RC, Rugg MD (2000) The effect of cholinergic receptor blockade by scopolamine on memory performance and the auditory P3. J Psychophysiol 14:11-23

Price GW, Michie PT, Johnston J, Innes-Brown H, Kent A, Clissa P et al (2006) A multivariate electrophysiological endophenotype, from a unitary cohort, shows greater research utility than any single feature in the Western Australian family study of schizophrenia. Biol Psychiatry 60:1-10

Pritchard W, Sokhadze E, Houlihan M (2004) Effects of nicotine and smoking on event-related potentials: a review. Nicotine Tob Res 6:961-984

Riekkinen P Jr, Paakkonen A, Karhu J, Partanen J, Soininen H, Laakso M, Riekkine P Sr (1997) THA disrupts mismatch negativity in Alzheimer disease. Psychopharmacology 133:203-206

Rinne T, Alho K, Ilmoniemi RJ, Virtanen J, Naatanen R (2000) Separate time behaviors of the temporal and frontal mismatch negativity sources. NeuroImage 12:14-19

Risch SC, Horner MD, McGurk SR, Palecko S, Markowitz JS, Nahas Z, DeVane CL (2007) Double-blind donepezil-placebo crossover augmentation study of atypical antipsychotics in chronic, stable schizophrenia: a pilot study. Schizophr Res 93:131-135

Rosler M, Anand R, Cicin-Sain A, Gauthier S, Agid Y, Dal-Bianco P, Stahelin HB, Hartman R, Gharabawi M (1999) Efficacy and safety of rivastigmine in patients with Alzheimer's disease: international randomised controlled trial. BMJ 318:633638

Sarter M, Lustig C, Taylor SF (2012) Cholinergic contributions to the cognitive symptoms of schizophrenia and the viability of cholinergic treatments. Neuropharmacology 62:1544-1553

Schiff S, Valenti P, Andrea P, Lot M, Bisiacchi P, Gatta A, Amodio P (2008) The effect of aging on auditory components of eventrelated brain potentials. Clin Neurophysiol 119:1795-1802

Schubert MH, Young KA, Hicks PB (2006) Galantamine improves cognition in schizophrenic patients stabilized on risperidone. Biol Psychiatry 60:530-533

Semlitsch HV, Anderer P, Schuster P, Presslich O (1986) A solution for reliable and valid reduction of ocular artifacts, applied to the P300 ERP. Psychophysiology 23:695-703

Shekhar A, Potter WZ, Lightfoot J, Lienemann J, Dubé S, Mallinckrodt C, Bymaster FP, McKinzie DL, Felder CC (2008) Selective muscarinic receptor agonist xanomeline as a novel treatment approach for schizophrenia. Am J Psychiatry 165:1033-1039 
Simons CJP, Sambeth A, Krabbendam L, Pfeifer S, Van Os J, Riedel WJ (2011) Auditory P300 and N100 components as intermediate phenotypes for psychotic disorder: familial liability and reliability. Clin Neurophysiol 122:1984-1990

Souza VB, Muir WJ, Walker MT, Glabus MF, Roxborough HM, Sharp CW, Dunan JR, Blackwood DH (1995) Auditory P300 eventrelated potentials and neuropsychological performance in schizophrenia and bipolar affective disorder. Biol Psychiatry 37:300 310

Tandon R, Mann NA, Eisner WH, Coppard N (1990) Effect of anticholinergic medication on positive and negative symptoms in medication-free schizophrenic patients. Psychiatry Res 31:235241

Tandon R, DeQuardo JR, Goodson J, Mann NA, Greden JF (1992) Effect of anticholinergics on positive and negative symptoms in schizophrenia. Psychopharmacol Bull 28:297-302

Thomas C, vom Berg I, Rupp A, Seidl U, Schroder J, Roesch-Ely D, Kreisel SH, Mundt C, Weisbrod M (2010) P50 gating deficit in Alzheimer dementia correlates to frontal neuropsychological function. Neurobiol Aging 31:416-424
Turetsky BI, Cannon TD, Gur RE (2000) P300 subcomponent abnormalities in schizophrenia: III. Deficits in unaffected siblings of schizophrenic probands. Biol Psychiatry 47:380-390

Turetsky BI, Bilker WB, Siegel SJ, Kohler CG, Gur RE (2009) Profile of auditory information-processing deficits in schizophrenia. Psychiatry Res 165:27-37

Umbricht D, Krljes S (2005) Mismatch negativity in schizophrenia: a meta-analysis. Schizophr Res 76:1-23

van der Stelt O, Lieberman JA, Belger A (2005) Auditory P300 in high-risk, recent-onset and chronic schizophrenia. Schizophr Res 77:309-320

Wezenberg E, Verkes RJ, Sabbe BG, Ruigt GS, Hulstijn W (2005) Modulation of memory and visuospatial processes by biperiden and rivastigmine in elderly healthy subjects. Psychopharmacology 181:582-594

Williams TJ, Nuechterlein KH, Subotnik KL, Yee CM (2011) Distinct neural generators of sensory gating in schizophrenia. Psychophysiology 48:470-478

Zouridakis G, Boutros NN (1992) Stimulus parameter effects on the P50 evoked response. Biol Psychiatry 32:839-841 